\title{
TELEPHONE LINE WORK IN THE UNITED STATES.
}

\author{
By E. S. Byng, Member.
}

(Paper first received 5th September, and in final form 10th October, 1921; read at THE INSTITUrron 17th November, before the NORTH-EASTERN CENTRE 14th November, before the Liverpoor Sub-CENTRE 21 st November, and before the NORTH MidLAND CENTRE 29th November, 1921, also before the NORTH-WESTERN CENTRE 10th January, 1922.)

\section{SUMMARY.}

The object of this paper is to place before members of the Institution observations made during a trip to the United States upon some of the practices adopted in line construction work. The treatment is mainly descriptive and, in general, no attempt is made to estimate the advantages or disadvantages of American telephone methods in comparison with those adopted in other countries. The scope of the paper is indicated in the Table of Contents given below.

TABLE OF CONTHNTS.

(I). Introduction.

(II). Stalf organization.

(III). Development studies.

(IV). Design and lay-out of plant.

(V). Engineering and constructional methods.

(1) Pole routes.

(2) Aerial cables.

(3) Conduit routes.

(4) Underground cables.

(5) House cabling.

(6) Block cabling and wiring.

(7) Drop wiring.

(VI). Transport.

(VII) Mechanical and labour-saving devices.

(VIII). Maintenance.

(IX). Conclusion.

\section{SECTION I.}

INTRODUCTION.

After the author's return from a recent visit to the United States of America, it was suggested to him that in view of the difference between the methods of telephone line construction adopted in the two countries, a paper describing the essential features of the presentday practice in the United States would prove of interest to British telephone engineers.

The methods of construction employed by the British Post Office are well known and are fully described in the several technical instructions issued by the Post Office Engineering Department. The methods adopted in America are, however, not so well known in this country, and an account of their distinctive features will, it is hoped, form the basis of a useful discussion.

In America, the home of the telephone, the possibilities of the invention were quickly appreciated and expert skill was bestowed upon its scientific development from its inception. These conditions may have had a great deal to do with the rapid progress of the telephone in the United States. That country now contains about 70 per cent of the telephones of the world, and the engineers concerned have therefore enjoyed a better opportunity of developing and improv- ing their plant methods than has been afforded elsewhere. Their work has been carried on in comparatively new cities which were growing rapidly, and among people who regarded the telephone not as a luxury but as a necessity of business and social life. The field, moreover, was left open to commercial enterprise. Telephone development in America was thus stimulated to a degree to which no other country affords a parallel.

\section{SECTION II.}

\section{Staff Organization.}

In order that the evolution of telephone practice in America may be understood, the organization in force will be briefly indicated. The American Telephone and Telegraph Company (referred to hereafter as the "A.T. \& T. Co.") and its associated and connecting companies, constituting what is commonly known as the Bell System, control approximately 12600000 telephone stations. In addition, there are about 900000 stations owned by independent companies, not connected in any way with the Bell System, but competing directly with it in certain territories. The entire country is covered by these associated companies.

Each company has its local organization, the operating side being generally divided into 4 major divisions, i.e.
(1) Engineering.
(2) Plant.
(3) Traffic.
(4) Commercial.

The chief officer of each department is directly responsible to a vice-president or general manager of the company. Fig. 1 shows the organization of one of these companies.

The allocation of the work among these departments will be understood by the following outline of their respective responsibilities :-

\section{(1) Engineering Department.}

(a) The technical standards employed in the design, construction, and operation of the plant.

(b) Preparing the exchange and toll fundamental plan.

(c) Preparing the provisional estimate.

(d) Inventories and appraisals and other work on rate cases.

(e) Recommending sites for buildings, preparing general plans and estimates for buildings, and advising architects when necessary.

( $f$ ) Preparing specifications and estimates for centraloffice equipment in conjunction with the traffic engineer and the Western Electric Company. 
(g) Study and application of the technical standards for construction materials and methods, equipment, transmission, and protection, and other general engineering standards recommended by the A.T. \& T. Co., and for providing the Plant Department with the necessary instructions with respect thereto.

(h) Review and approval (or constructive criticism) of plans and estimates of cost for extensions and additions to the outside plant prepared by the Plant Department.

(2) Plant Department.

(a) Recommending all outside plant extensions and additions to meet contemplated growth; and making plans and estimates of costs for the construction and reconstruction work involved. Toll and trunk circuit requirements are set up by the Traffic Department, and those relating (c) Traffic data for the fundamental plan.

(d) Handling of traffic.

(e) Training of operators.

(f) Observation and inspection of the service rendered.

(g) Arrangements for co-operating with the Traffic Departments of other companies of the Bell System and for giving proper assistance to, and co-operating with, connecting companies in traffic matters.

(4) Commercial Department.

(a) Determination of local rate areas and rates, and suburban toll rates.

(b) Commercial basis for the fundamental plan.

(c) Compilation, publication, and distribution of telephone directories.

(d) Publicity and advertising work.

(e) Commercial relations with connecting companies.

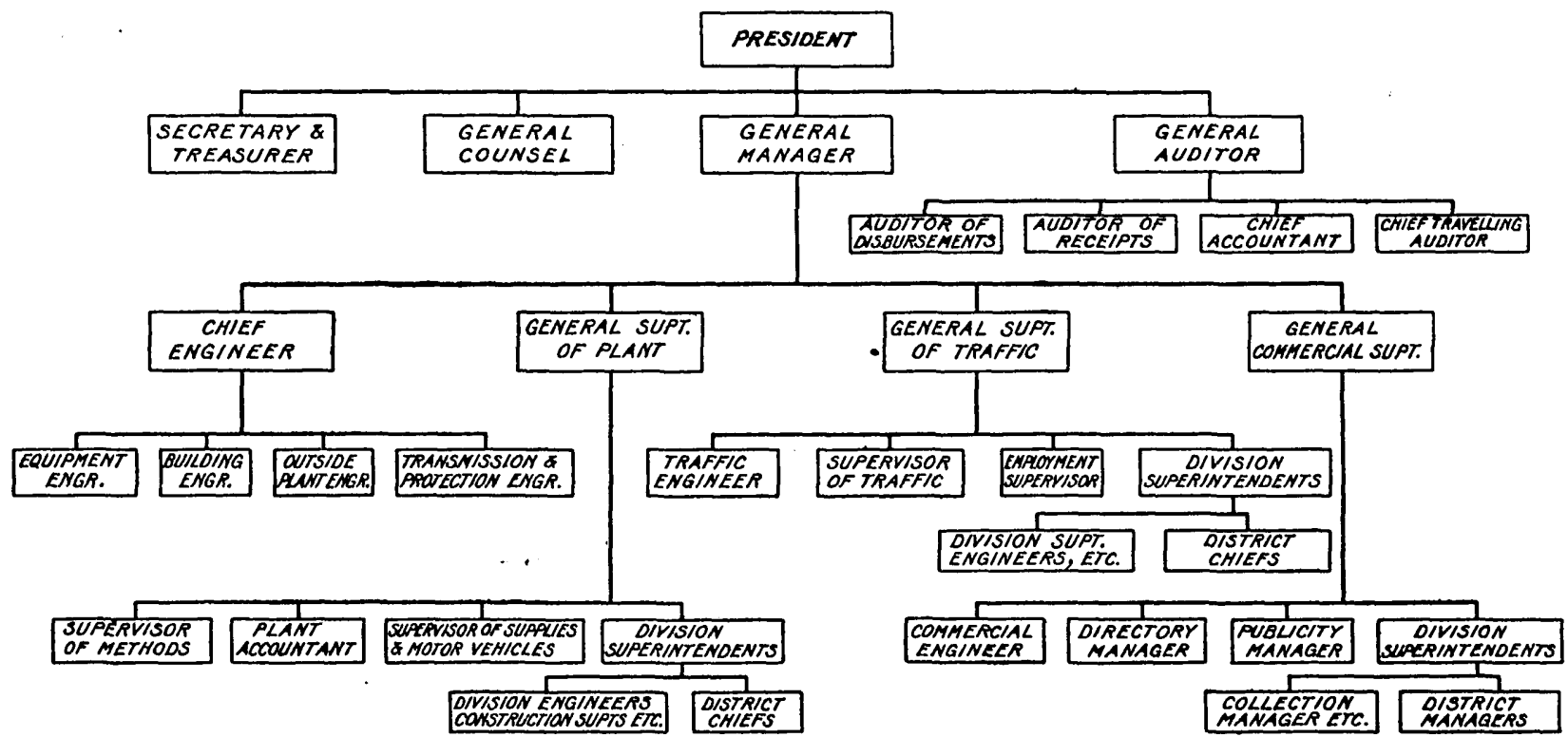

FIG. 1.-Bell Telephone System : typical staff organization of an operating company.

to station growth by the Commercial Department.

(b) Keeping the plant records.

(c) Obtaining all rights of way.

(d) Construction of the line and station plant, and in certain cases (the majority of which involve only minor additions), the installation of central-office plant.

(e) Maintenance of the telephone and real-estate plant in its entirety, including such items as general equipment, tools, and vehicles.

(f) Ordering and distributing material and supplies, making plant pay-rolls, and keeping account of the plant use of material and labour.

(3) Traffic Department.

(a) Recommending all additional central-office equipment and all additional trunk and toll circuits required by the growth of business.

(b) Study and application of standard traffic practices recommended by the A.T. \& T. Co. $(f)$ Predicting growth in business.

$(g)$ "Selling the service"-a term comprising canvassing, collecting, etc.

The responsibilities of the Plant, Traffic, and Commercial Departments are necessarily distributed over the territory of each company, and the staffs are correspondingly located. The Engineering Department, however, is a general head-quarters staff and is so placed in the organization that all projects for addition to the plant must receive the chief engineer's approval before being acted on by the Executive Committee. In the last analysis no small measure of direct responsibility rests with the chief engineer in the matter of producing a fair return.

The details of the organization which reports to the divisional superintendents depend very largely upon the size of the territory controlled. In some cases a greater amount of functional, rather than sectional organization, is advisable; in other cases, where the 
centres are widely apart, sectional organization appears to have many advantages.

Each associated company furnishes the exchange telephone service for the cities, towns, and villages situated within the territory over which it operates; it also provides a local trunk service between one place and another within the same territory. Systems of long-distance trunks between towns in different territories are furnished by the Long Lines Department of the A.T. \& T. Co. Although it forms a part of the main company, this department is managed practically as a separate company and has its own organization covering the whole of the country.

The A.T. \& T. Co. constitutes the central controlling organization for the whole of the Bell System. The technical side of the head-quarters staff consists of two main departments, the Department of Development and Research, and the Department of Operation and Engineering, each under the charge of a vice-president of the company. These departments act in an advisory and consultative capacity for the associated companies, and it is due to this organization that a standardized telephone system has been established throughout the United States.

The officials of the associated companies are in close touch with the general departments, and thus keep themselves informed of the best practice in their particular branch of telephony. The associated companies do not undertake any broad technical development, research, or standardization work, this duty being performed by the central organization.

In addition to the Technical Department of the central organization, the engineering staff of another of the associated companies in the Bell System, the Western Electric Company, is called upon to develop new devices and to carry out all laboratory investigations and tests. The Western Electric Company is responsible for the manufacture of all telephone apparatus and cable for the Bell System; it also acts as purchasing agent for all auxiliary supplies conforming to specifications prepared by the A.T. \& T. Co.

\section{SECTION III.}

Development Studies.

A forecast of the development for many years ahead is necessary in order to secure an efficient telephone system. This forecast forms the basis for a number of important phases of planning and engineering, such as the lay-out of exchange areas, current-rate treatments, fundamental plant and equipment plans, and provisional estimates and budgets.

The fundamental plan, and the collateral studies based on the fundamental plan data as developed, are expected to indicate :-

(a) The general ultimate conduit system;

(b) The locations of existing and proposed central offices ;

(c) The economy of establishing new branch offices or of enlarging or replacing existing central offices, when the location of the office is involved; and (d) The most appropriate design of subscribers' and trunk cable plant.

The investigation required for these purposes is known as a "Commercial Survey," and is made by the Commercial Engineering Department on the following lines :-

(1) An analysis of all existing telephone subscribers is prepared from existing records. As American cities are usually laid out on a rectangular block plan, a separate record is made for each block, which forms a convenient unit for telephone distribution. Details of the class of service are also given.

(2) A survey of each block is made to ascertain whether the existing subscribers should be classed as :- (a) "Business," and, if so, the exact class of business is recorded; or $(b)$ "Residence," in which case particulars as to the number of families, type of house (whether private, flat, apartment, etc.), and rental value per month are obtained. At the same time, similar information is compiled of all nonsubscribers in the block.

(3) Two sets of ordnance maps on a suitable scale are prepared, one to show the recognized " wards" into which the town is divided, and the other the areas where the conditions are considered to be uniform. The latter were originally known as "homogeneous" sections, but the term now generally used is " market" sections. It is usually found that there are certain neighbourhoods the character of which is more or less uniform; for example, where people of one race form a colony in a town. Further, one district may be purely artisan, whereas another may contain nothing but high-class residential property; and so on. The maps showing the "wards" and " markets" sections are superimposed to obtain what is known as " working" sections, which are in turn used as the basis for the study of development. A " working" section will contain a number of blocks, but it can, if necessary, be further sub-divided for the purpose of accuracy in final distribution.

(4) The information obtained under (2) is summarized for each "working" section, so that the total number of subscribers and non-subscribers can be obtained in any form subsequently required ; that is to say, for the town as a whole, in "wards," or in " market" sections.

(5) The various local characteristics are considered; for example, census figures for population and number of families; statistics regarding school enrolments ; birth rates; death rates; reasons for excessive growth or retardation; the position of a town in relation to neighbouring towns; transportation facilities; industrial activities which may determine the growth of the town for the next 20 years; the probable trend of building development; the ratio of the number of telephones to the number of 
families compared with the proportion in towns similarly situated; and, finally, the effect of possible increases or decreases in the telephone charges upon the use of the service by the various classes of families. Forecasts of telephonic growth are made in relation to "families" rather than to population, as they are considered to afford a more reliable standard.

(6) On the basis of a comprehensive study of all such local characteristics by the Commercial Engineering Department, a map is prepared showing the estimated development for each "working" section during the planning period decided upon for the town concerned. For a fast-growing territory a 15-year figure is taken; under normal conditions, however, the period is 20 years. Intermediate figures for 6-year and 12-year periods are also given, as these facilitate the preparation of the fundamental plan.

\section{SECTION IV.}

Design and Lay-out of Plant.

The fundamental plan is intended to show the general lay-out of telephone plant in a city over a definite period of 15 to 20 years, in accordance with the development study. Such a plan gives the situation of the exchanges and conduit routes, both existing and proposed. The new conduit routes are laid out so as to give the most direct path from the exchange to any block, following a definite plan of distribution. The disposition of the existing plant, being a controlling factor in many instances, is also taken into consideration. The fundamental plan does not attempt any refinement of detail; it is a rough conjecture of the probable telephone requirements. The proposed main routes are indicated, but the actual installation is not begun until it is required by growth, street improvements, or local regulations. In other words the fundamental plan serves as a general guide to the plant engineers, so that, when a plant extension has to be made, it may be of the proper size and correctly arranged.

Fundamental plans are usually reviewed every five years, so that, as far as possible, a comprehensive, consistent, and economical system of distribution is secured. In general, an underground conduit system is adopted in all main thoroughfares and business streets ; in the outskirts of a city, and for distribution work, aerial cables are used extensively. The limiting lengths of the various sizes of copper wire, which are dependent upon transmission requirements, are determined for the exchange area as a whole.

The block-building system lends itself very conveniently to a symmetrical lay-out of plant. As already indicated, the plant engineer takes a block as a unit for telephone distribution. The dimensions of a block are generally $600 \mathrm{ft}$. long by $400 \mathrm{ft}$. wide. In the business sections, where a large number of circuits are required, a block is divided into several sections, each of which is served by direct " house" cables. Where the telephone density is not so great, block-wiring- either external or internal-is adopted. In "thin" areas it may be economical to arrange the distribution from short poles erected either in the alleys within the block or in the roadway between adjacent blocks. The methods of distribution are described in more detail in Section V.

Reference has been made to the use of aerial cables. Ever since the days of overloaded open-wire routes the advantages of the aerial cable as an economical means of providing telephone service under certain conditions have been realized. On the other hand, aerial cable was at one time considered to be a transition stage between open-wire and underground construction. Owing to ring cuts, crystallization of the lead sheath which occurs at poles, and other defects which were frequently the cause of breakdowns, it was deemed advisable in many cases to place important long-distance cables underground in order to ensure continuity of service. As a result of close investigation the defects mentioned were gradually eliminated in the case of subscribers' cables, and the success thus obtained caused the engineers to turn their attention to long-distance cables, with the result that it is now settled policy, where local conditions permit, to run all long-distance cables aerially. The advantages and disadvantages of aerial cable, as compared with underground cable, are further discussed in the latter portion of Section V (2).

The question of the actual type of plant to be adopted is always considered from the standpoint of economy ; but, in addition, features of safety, the quality of service to be provided, and the desire to set up conditions satisfactory to the public, are important considerations which are taken into account. In cost studies both the first costs and the annual costs are included for a period over which unequal facilities exist, or up to a time when a definite procedure will be followed regardless of which plan may be adopted at the outset. In this manner the required facilities can be secured with a minimum expenditure throughout the life of the plant involved.

Subscribers' cables are referred to as either main or distribution. The term "main cable" is considered to mean the large sizes of cable radiating from an exchange, into which the distribution cables are jointed. The distribution cable is the branch cable which feeds the actual distribution points. The standard sizes of No. 22 B. \& S. gauge cable $(10 \mathrm{lb}$.) range from 25 to 900 pairs, plus 1 per cent for defects. If a greater number of pairs is required in a $2 \frac{5}{8}$-inch diameter of lead sheath-known as "full-size" cable -No. 24 B. \& S. gauge ( $\left(i \frac{1}{2}\right.$ lb. $)$ conductor is used. With these conditions a 1200 -pair cable can be obtained. The latter cables are used in fast-growing areas and in the main runs of larger cities where transmission requirements pernit. Experiments are now being conducted in order to ascertain if it is possible to manufacture and use a No. 27 B. \& S. gauge cable $\left(3 \frac{1}{4} \mathrm{lb}.\right)$ in large telephone cables planned for 1500 pairs.

In all subscribers' cables a colour code is adopted. For main cables the distinctive coloured pairs are arranged in groups of 100 , plus 1 per cent, so as to facilitate testing and numbering through. For a 
1200-pair cable the colour code for the paper insulation is as follows :-

\begin{tabular}{|c|c|c|}
\hline Group & No. of Pairs & Colours of Wires \\
\hline & $\int 100$ & Red-White \\
\hline 1 & $\begin{cases}1 \\
2\end{cases}$ & Red-Orange \\
\hline 2 & 101 & Blue-White \\
\hline 3 & 101 & Orange-White \\
\hline 4 & 101 & Green-White \\
\hline 5 & 101 & Red-Blue \\
\hline 6 & 101 & Red-Green \\
\hline 7 & 101 & Red-White \\
\hline 8 & 101 & Blue-White \\
\hline 9 & 101 & Orange-White \\
\hline 10 & 101 & Green-White \\
\hline 11 & 101 & Red-Blue \\
\hline 12 & $\int 100$ & Red-Green \\
\hline 12 & $\{1$ & Red-Orange \\
\hline
\end{tabular}

The paper wrapping is applied to the wires in a spiral and therefore no cotton binding is required to hold it in place. Two wires are twisted together to form a pair, and the pairs are stranded in layers. In "quadded" cable, the two pairs forming a "quad" are each served with a cotton binding, but there is no serving over the " quad."

Some years ago, in America, it was considered that lead alone did not possess the mechanical properties essential for a satisfactory cable sheath. The requirements were that the sheath should be capable of enduring a reasonable amount of abrasion, of bending without kinking, and also of resisting chemical action. It was found that an alloy of 97 per cent lead and 3 per cent tin had the requisite mechanical strength, even when the thickness of the sheath was reduced. Owing to the increasing price of tin, experiments were made with other alloys, resulting in the final adoption of an alloy of 99 per cent lead and 1 per cent antimony for cable sheaths of both overhead and underground telephone cables. Before the cable is sheathed a layer of red paper is placed over the complete core for the purpose of enabling workmen to separate scrapped sheath, so that antimony-alloy sheath and tin-alloy sheath may not become mixed. It also serves as an indication to jointers that the sheath contains antimony.

In planning the cable lay-out in the centre of a large city it is not usual to consider diminishing or tapering main cables. The objection to opening main cables for the purpose of transferring branch cables to afford relief, or for connecting new branches, has been removed by the provision of large stubs. The method of jointing stub cables is dealt with in Section V (4).

Wherever it is anticipated that branches will be jointed-in at any later date, arrangements are made to bring out a stub cable containing a number of pairs equal to the sum of the ultimate number of pairs in the branch cables, plus a percentage of pairs for flexibility and changes in the distribution. The size of the stub cables, however, does not exceed that of the cable to which they are connected, and preferably they are arranged in even hundreds, to comply with the colour code. The distribution at a given point is confined to one cable, and the cable is so arranged that all its branches are in adjacent manholes. In practice the same numbers are brought out at two or more points, and when relief cable is provided care is taken to avoid any change in the numbering of the cables at the main frame. The first cable feeds a permanent area between the exchange and the suggested relief point, and also a temporary area beyond this point. When the further cable is installed, the original cable is cut at the point of relief without the necessity of transferring any of the stubs or branches. This arrangement is shown diagrammatically in Fig. 2.

In a rapidly-growing territory the question of relief is often considered when the cable is serving 60 to 65

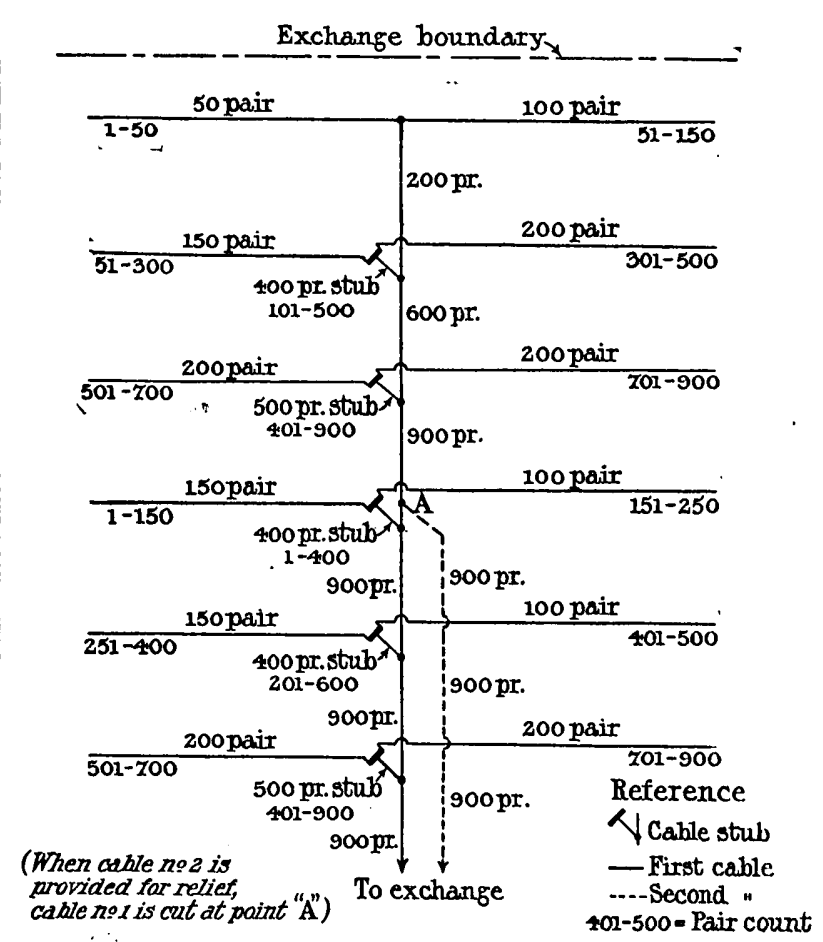

Fig. 2.-Cable lay-out.

per cent of its total pair capacity. It rarely happens that the construction staff is obliged to open joints in the main cables, this process being avoided on account of the possibility of introducing defective pairs and the danger of lowering the insulation resistance.

The plant engineer makes himself familiar with all the details of the plant within his jurisdiction, and by means of card records is kept informed as to the "fill" of the cables, so that new development studies may be made which will enable him to plan any construction work simultaneously with the relief of congestion. Unless he has this detailed knowledge of the plant and also of the character of the growth, it is impossible for him to plan an efficient telephone system. To this end he has, in addition to the fundamental plans, a series of maps giving detailed information of all existing plant. These are known as "plant study maps" and 
are intended primarily as a guide to the plant engineer in efficiently arranging for relief and the extension of plant. There is very close co-operation between plant engineers and the commercial department, ensuring that the more urgent work receives prior attention, and that canvassing does not take place before the necessary plant is available.

\section{SECTION $V$.}

\section{ENgineering and Constructional Methods.}

\section{(1) Pole Routes.}

(a) Poles.-The poles, which are generally of chestnut, white, red, or Western cedar, are classed " A" to " $G$," according to the circumference at the top and the circumference $6 \mathrm{ft}$. from the butt. Reinforced concrete and iron poles are not used, as at present timber can be readily obtained direct from the forests. Where the site of erection is remote from a forest or pole yard, creosoting is regarded as a measure of economy. Locally-hewn timber is frequently butt-treated with creosote oil. A gain of 5 to $\mathbf{1 5}$ years may be expected, depending upon the treatment applied. Brush treatment gives a gain of approximately 5 years, while open-tank treatment, providing for the penetration of the preservative to approximately $\frac{1}{4}$ inch, will give an increase in life of 15 years or more.

The provision of a reinforced-concrete belt round the pole at the ground line is considered to be beneficial in certain cases, but, unless it is properly applied, moisture will accumulate between the reinforcement and the pole and, instead of prolonging the life of the pole, will cause more rapid deterioration.

Main telephone routes generally follow the public roadways, but short cuts across country are frequently made where rights-of-way can be obtained. When negotiating for private easements a lump sum payment per pole, rather than an annual rental per pole, is offered in complete discharge of the required facility. The amount paid for the facility looks more attractive to the owner, and the clerical work involved in making periodical payments is abolished. Wherever possible the form signed by the owner also gives the telephone company the right to trim any trees along the route so as to ensure a clearance from the wires of at least 18 inches. When taking a main route through a forest an attempt is made to minimize the number of faults arising from contact with branches and falling trees by securing a $40-\mathrm{ft}$. cut through the forest, i.e. a 20 -ft. clearance on either side of the route. The size of pole ranges from $30 \mathrm{ft}$. to $35 \mathrm{ft}$. for main routes, and is about $25 \mathrm{ft}$. for rural lines. Where a pole route is to be used for distribution within blocks-a case referred to as a " rear property pole line"-the length of pole is frequently only $20 \mathrm{ft}$.

Poles are spaced at from 100 to $150 \mathrm{ft}$. apart, according to the number and weight of conductors to be carried. Except in special cases long spans are not permitted, as the cost of such special construction is an item of prime importance, in addition to the serious expense of maintenance during bad weather conditions. On toll line routes the stouter poles, classes $A$ and $B$, are used and are spaced 100 to $110 \mathrm{ft}$. apart. The tendency to-day is to use the former for open-wire toll lines, and the latter for cable lines. Pole roofs are not used, and it is not considered necessary to provide earth wires as protection against lightning.

Before a pole is erected, locations are decided well in advance of the construction gang by means of ranging rods. Circular pole-holes are excavated by means of special spoon-shaped shovels and long bars. The hole is sufficiently large to admit of the use of the tamping iron all round the pole, but less ground is disturbed than when a stepped rectangular hole is excavated. Pike poles and a tool called the "dead man" are used for pole erection in preference to ladders if a derrick operated from the rear of an automobile truck is not available. In favourable circumstances a construction gang of 12 men can excavate for and erect thirty $25-\mathrm{ft}$. poles (each carrying one arm) in an 8-hour day, without

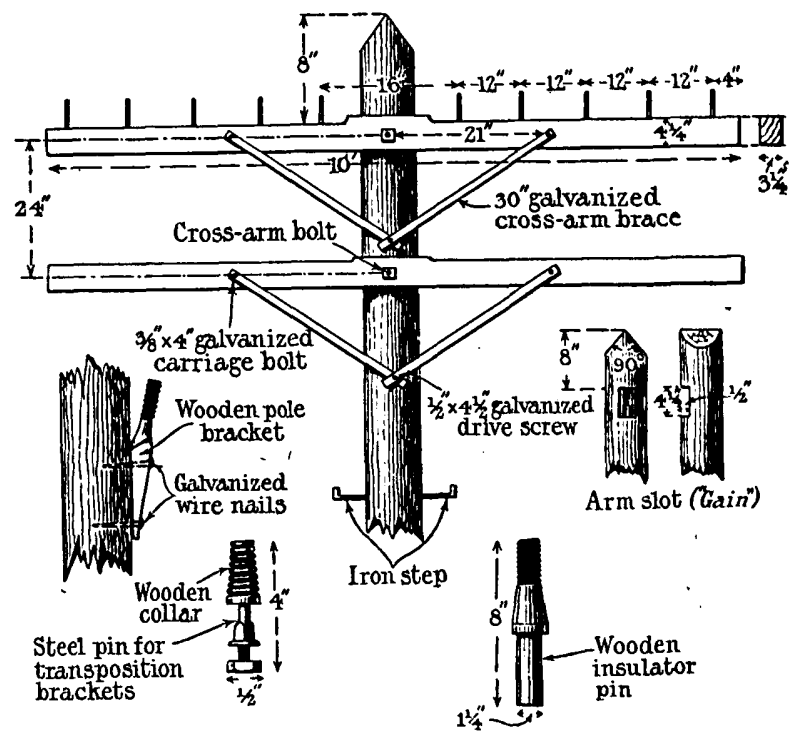

FIG. 3.-Pole fittings.

resource to the mechanical labour-saving devices mentioned in Section VII.

(b) Arms.-For exchange and toll line construction the standard arm has a normal capacity of 10 wires and is known as a 10-pin cross-arm. Two iron straps, known as " cross-arm braces," are used for preventing tilting of the arms; they do not interfere with the erection of the wires. Fig. 3 shows the fittings for a pole carrying two 10-wire arms. Double sets of arms are used at corner poles with a pull of $35 \mathrm{ft}$. or more, and also at certain special points, such as railway crossings, long spans, and test-poles.

(c) Pole brackets. - Where a maximum of only two or three circuits is required for some years ahead, wood-pole brackets are used, as they save the cost of providing a 10-wire arm.

(d) Pole steps.-It is not usual to provide pole steps on through routes. Linesmen are provided with climbing irons. At terminal poles and distribution points arrangements are made for permanent stepping.

(e) Staying.-There are several types of stay rod 
(guy rod) which can be installed by means of earth borers, some of which are shown in Fig. 4. In general these rods give very good service. They can be used for anchoring any size of stay wire, with the possible exception of $16000-\mathrm{lb}$. wire. On heavy lines, where the patent rod is not considered to be satisfactory and $16000-1 b$. strand wire will be required, logs or planks are used to form the anchor. In all types of stay rod the top forms a closed ring, approximately 6 inches above the ground. The guy wire or strand, which is used for staying purposes and also for the suspension
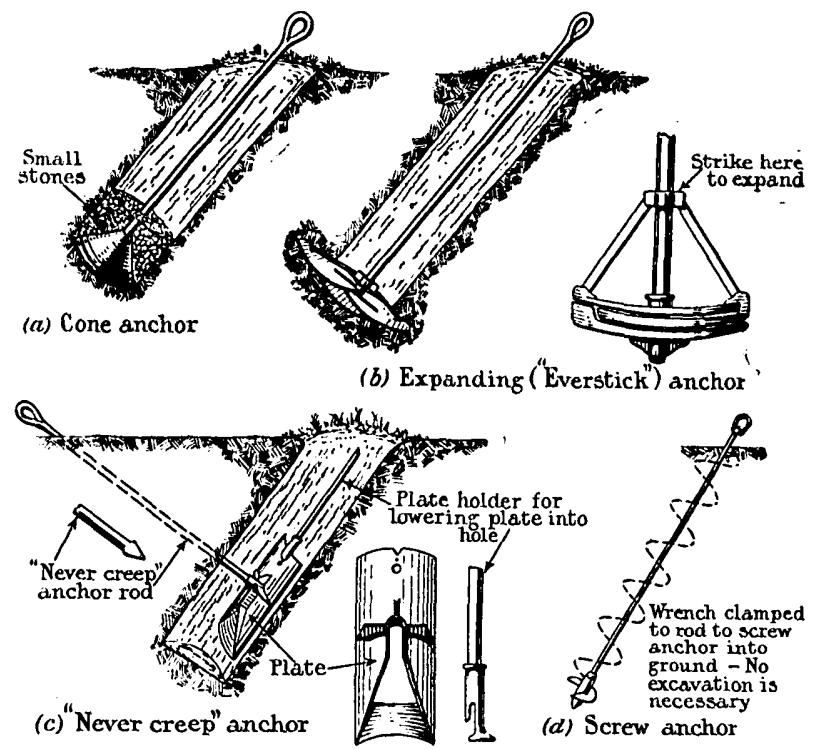

FIG. 4.-Types of patent stay rods (anchors).

of aerial cables, is composed of seven strands of galvanized mild stecl wire formed into a cable of the following sizes :-

\begin{tabular}{r|c|c|c|c} 
Size & $\begin{array}{c}\text { Diameter } \\
\text { of Strand }\end{array}$ & Gauge of Wire & $\begin{array}{c}\text { Minimum } \\
\text { Breaking } \\
\text { Weight }\end{array}$ & $\begin{array}{c}\text { Weight } \\
\text { per } \\
1000 \mathrm{ft}\end{array}$ \\
\begin{tabular}{r|c} 
lb. \\
2200
\end{tabular} & $\begin{array}{c}\text { in. } \\
3 / 16\end{array}$ & 16 B.W.G. & 2300 & 75 \\
6000 & $5 / 16$ & 12 B.W.G. & 6000 & 210 \\
10000 & $3 / 8$ & 11 B.W.G. & 11500 & 295 \\
16000 & $7 / 16$ & 9 N.B.S. & 18000 & 415 \\
\hline
\end{tabular}

A turnbuckle, swivel, or other device for adjusting the tension on the wire after installation is not considered to be necessary. The wire is terminated by one or more 3-bolt guy clamps at each end. These clamps are fixed very quickly with the aid of a small pair of blocks which pull up the wire to the required tension. I'oles situated at angles are given a slight set and, in practicc, it is scldom found necessary to release any clamp subsequently for the purpose of tightening the wirc. Strain plates are placed round the pole at the point of making off in the case of $10000-1 \mathrm{~b}$. and $16000-1 b$. strand. Where a stay wire is attached to a pole carrying electric light wires, or is immediately adjacent thereto, a strain insulator is inserted in the guy wire as a protection against accidents.

( $f$ ) Insulator bolts. - Insulator bolts (pins) are constructed of locust wood, a local and durable timber. The pin is simply driven into the 11 -inch hole provided in the arm, and held in place by a nail. On transposition brackets steel pins are used, but they are fitted with wood collars to enable the standard type of insulator to be used.

(g) Insulators.-Various materials have been tested in the search for an insulator suited to American conditions, and glass, in conjunction with wooden pins, has been found to give the best results. At one time single-shed insulators were used exclusively, but, as the insulation resistance was found to be insufficient for high-grade toll line work, the double-petticoated insulator was introduced. The latter is now used when running or transferring all loaded circuits, and also in non-loaded circuits over 100 miles in length. Its use may also be justified on shorter circuits when insulation conditions are very severe. On subscribers' circuits the single-shed insulator is quite satisfactory. Double-shed porcelain insulators have been used, and there are still many in use; but these are considered obsolete, and glass is now the standard for all purposes.

(h) Class of wire.-For toll lines a No. 8 B.W.G. (435 lb.) or No. 12 N.B.S. (173 lb.) hard-drawn copper wire is used almost invariably, but for exchange circuits either No. 12 B.W.G. (165 lb.) and No. 14 B.W.G. (96 lb.) galvanized iron wire, or No. 12 and No. 14 N.B.S. (102 lb.) copper wire is employed. Galvanized iron wire is adopted in slow-growing outer portions of large exchange areas, and in all portions of the smaller exchange areas subject to the following conditions:-

(i) That the anticipated development is less than 10 lines in a 15-year period.

(ii) That the iron wire will have a life of $S$ years or more.

(iii) That transmission requirements are fulfilled.

Where lines are exposed to moist air or the smoke from soft coal, experience has shown that iron wire will not last 8 years. Consequently copper wire has to be used for the majority of open-wire lines in the Eastern States.

Bronze and copper-clad steel are not used to any extent as overhead conductors, except as covered " drop" wires for distribution purposes. These covered wires are also adopted on subscribers' routes where the development studies indicate that the maximum number of circuits in a 5-year period will be six, and where the route does not exceed $1000 \mathrm{ft}$. in length. When only three or four of such leads are required arms are not provided, small iron brackets carrying porcelain knobs being fitted on the pole. The number of open wires for local routes is limited where possible to 30 , i.c. the full capacity of three 10-wire arms. When the number of circuits exceeds the figures mentioned it is probable that cable can be justified at the outset. The joint use of poles for telephone and electric supply wires is 
greatly encouraged. The advantages are mutual, particularly on small routes used for distribution purposes.

(i) Jointing and binding-in.-For jointing hard-drawn copper wires a copper sleeve (McIntyre) is almost universally used in preference to a twisted and soldered joint. For galvanized iron wire, steel tubes are used, but it is also standard practice to twist and solder. At straight-through insulators a piece of soft wire of the same material as the through wire is used for tying-in and binding the line wire.

(j) Termination of open wires on poles.-At distribution or opening-out points circuits are terminated on straight insulator pins. On exchange circuits No. 18 B. \& S. $(26 \mathrm{lb}$.) insulated bridle wire is used for terminations and cross-connections. On high-grade toll circuits a No. 14 B. \& S. (65 lb.) insulated wire is used. In both cases the covered wire is supported underneath the arms in small bridle rings. Prevention of leakage on high-grade toll circuits is effected, wherever bridle wire is used for terminating purposes, by the interposition of an additional insulator (made of a material known

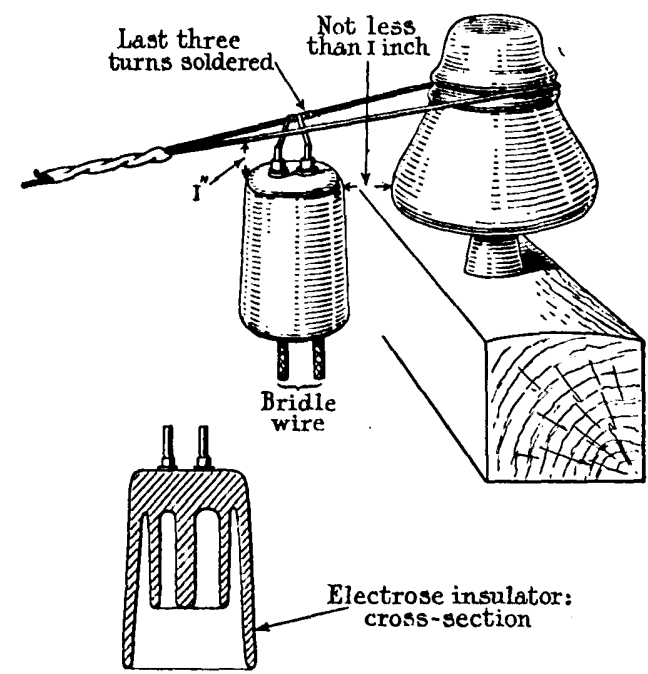

Fig. 5.-Termination of high-grade toll wire, using electrose insulator.

as " electrose") in conjunction with the glass insulators. The bridle wires are threaded through the metal tube inserts and soldered at the top, thus sealing the holes, as shown in Fig. 5.

(k) Superimposing.-On a toll or long-distance line practically every pair of physical circuits is used to obtain a third or phantom circuit by the installation of repeating coils at the terminating ends. The phantom circuit has been proved to be a better circuit than the side circuit, and is therefore a very profitable proposition. A further utilization of the plant is obtained by each of the four wires forming a group being separately composited for telegraph operation. A still further development is that by the application of "carrier" currents each pair of wires can be utilized for several simultaneous telephone or telegraph circuits. This advancement in the art greatly increases the value of open-line plant, but necessitates a high degree of efficiency in its construction and maintenance. (l) Transposition.-All open-wire circuits in America are run straight. Only one arm is therefore required on a pole route which carries five pairs of wires. A system of transposition is adopted for long-distance lines. Two methods of transposition have been worked out in a very thorough manner, one for "exposed" and the other for " unexposed " lines.

Apart from this method of avoiding electrical interference, measures are frequently suggested to the electric supply companies by the telephone companies for the elimination of the higher harmonics which from time to time cause serious electrical interference with telephonic speech. Each cause of trouble is studied as it arises, and the endeavour always is to reach an arrangement which is mutually satisfactory and compatible with economy.

The standard numbering of wires on a pole route of two 10-wire arms is given in Fig. $6(a)$. Wires 5,

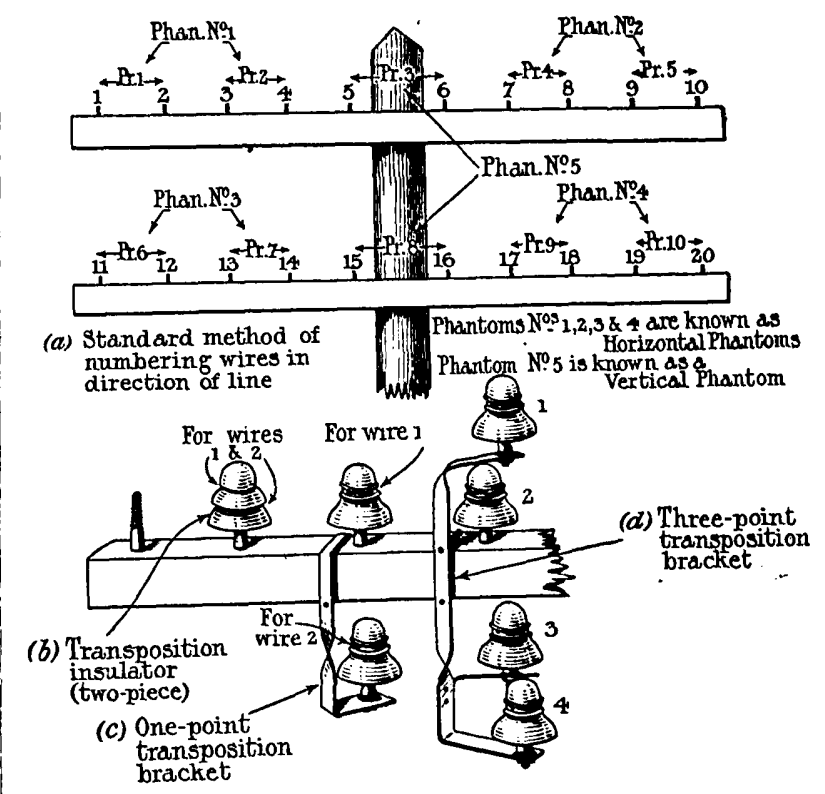

FIG. 6.-Numbering of wires, and transposition brackets.

6,15 and 16 comprise what is known as the "vertical phantom circuit."

For a single-circuit transposition on an ordinary toll or long subscribers' circuit a special type of transposition insulator is used. It consists of a 2-piece insulator, each piece having a groove. A special 9 -inch transposition pin carrying two sets of threads is necessary to provide sufficient clearance above the cross-arm.

On a high-grade toll circuit a bracket is fitted to carry the second wire. A special method of transposition is employed on lines which are included in a phantom group. Not only must the wires in the original metallic connection or side circuits be transposed, but the phantom circuit must be balanced by transposition against its own side circuits as well as against other phantom circuits on the same pole. A 3-point transposition bracket has been devised for this purpose. The three methods are illustrated in Figs. $6(b), 6(c)$, and $6(d)$. One method in which transpositions are 
made on side circuits and phantom circuits is shown in Fig. 7.

There are eight combinations possible for transposing the four wires forming a phantom group. The actual type of transposition and location in relation to other circuits is dccided for each route after survey. When the wires are erected by means of a running board the pairs can be transposed separately, or the position of the pairs changed for a phantom transposition simply by releasing the spring latch on the eye to which each pair is attached.

(m) Loading of open wires.-Until the advent of the repeater, the practice of loading long-distance lines was adopted in America for circuits using No. 8 B.W.G.
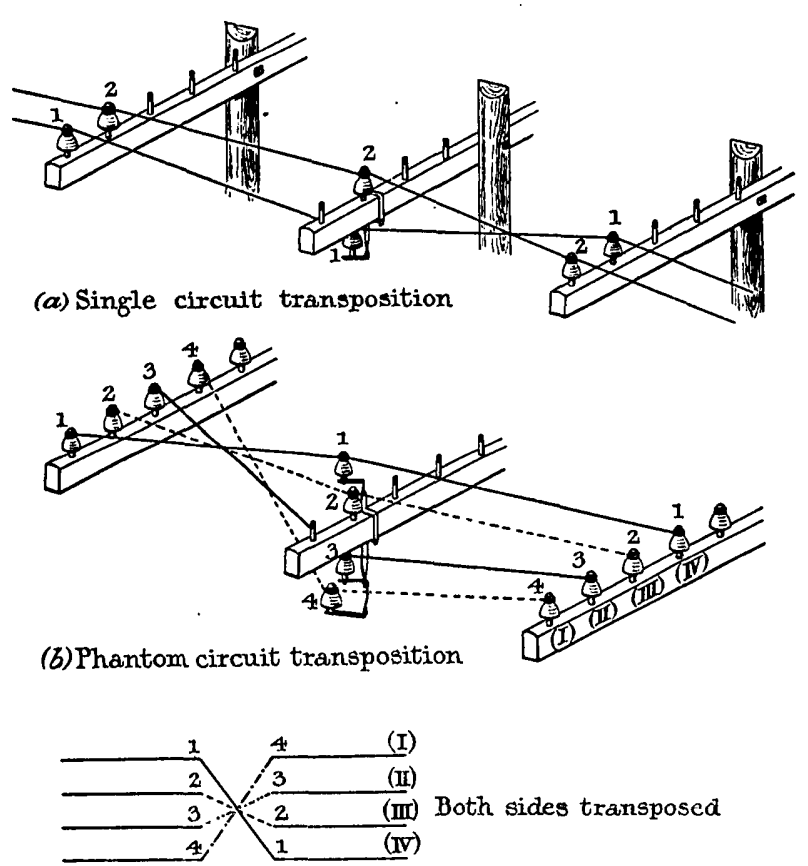

FIG. 7.-Methods of transposition.

and No. 12 N.B.S. copper. In the case of existing No. 8 B.W.G. circuits, where repeaters have since been installed, the loading coils have been removed, that is to say, the wires have been " unloaded." In the smaller size of wire, however, loading coils are required and are still being fitted in conjunction with repeaters. A complete unit of loading, which consists of three coils, two for the side circuits and one. for the phantom, mounted in a pot suitable for fastening to the pole, is used in conjunction with a lightning arrester to protect the coils.

\section{(2) Aerial Cables.}

The same general principles are followed in the installation of both exchange aerial cables and toll line aerial cables.

(a) Type and class of cable.-Cables containing smallgauge conductors No. $22 \mathrm{~B}$. \& S. (10 lb.) are supplied in two types, one for aerial use, and the other for underground use. The underground type is not used aerially on account of its low dielectric strength, and the use of the aerial type for underground purposes is not economical. The sheath, however, is the same in both cases. Cables containing conductors of $20 \mathrm{lb}$. and heavier are identical, whether for aerial or underground installation. The largest size of these cables can be installed aerially if required.

(b) Methods of suspension.-Before a suspension strand is run out all necessary guying is completed at terminal points, corners, road and railway crossings, and at extremities of long spans. Where a class A pole route is carrying one or two cables only, it is not generally considered necessary to fix storm stays. The suspension strand is the same as that used for guying, particulars of which were given in the table on

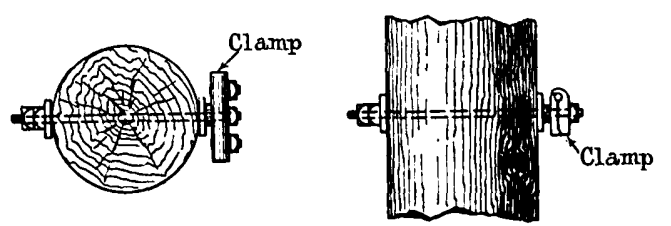

(a) Clamp

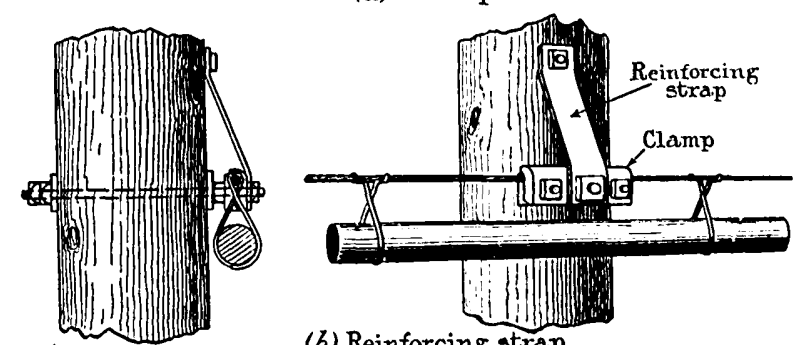

(b) Reinforcing strap

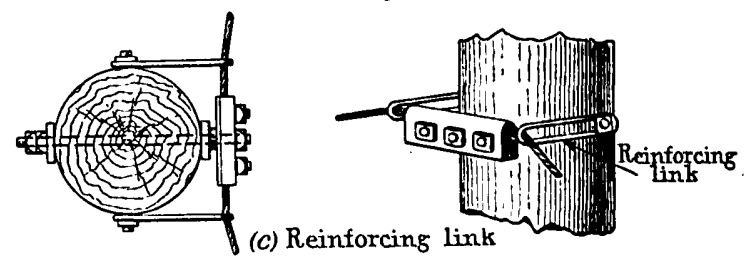

FIG. 8.-Suspension-strand fittings.

page 91. The sizes of strand required for various cables are given in the table below:-

\begin{tabular}{|c|c|c|c|}
\hline Size of Strand & $\begin{array}{l}\text { Maximum Size of } \\
\text { Cable; No. } 22 \text { B. \&. S. }\end{array}$ & $\begin{array}{c}\text { Maximum } \\
\text { Diameter } \\
\text { of Cable }\end{array}$ & $\begin{array}{l}\text { Maximum } \\
\text { Weight of C2ble, } \\
\text { per foot }\end{array}$ \\
\hline $6 \stackrel{\text { lb. }}{000}$ & 100-pair & $\begin{array}{l}\text { in. } \\
1 \frac{1}{16}\end{array}$ & $2 \cdot \frac{1 \mathrm{lb} .}{2 \cdot 25}$ \\
\hline 10000 & 300-pair & $1 \frac{3}{4}$ & $4 \cdot 95$ \\
\hline 16000 & Over 300-pair & Over $1 \frac{3}{4}$ & Over $4 \cdot 95$ \\
\hline
\end{tabular}

The strand is attached to the pole by means of a clamp. as shown in Fig. $8(a)$. Where the cable supported exceeds 2 inches in diameter a reinforcing strap is used [see Fig. $8(b)$ ]. At corner poles a reinforcing link is fitted as indicated in Fig. $8(c)$.

Where new poles are provided, the suspension strand 
is generally fixed about 14 inches from the top of the pole. If ultimately the route is to carry two cables, the strand for the first is erected on the same side of each pole throughout, and the second may then be run without crossing the first. Suspension strand is requisitioned in reels up to one mile in length. On a long-distance toll cable several miles of suspension strand can be erected, without actual termination, by making straight joints in the strand as shown in Fig. $9(a)$. Where the cable is terminated the strand is " made off" on the pole, as shown in Iig. $9(b)$. What is known as a "false dead end," constructed as shown in Fig. $9(c)$, is formed on the suspension strand at
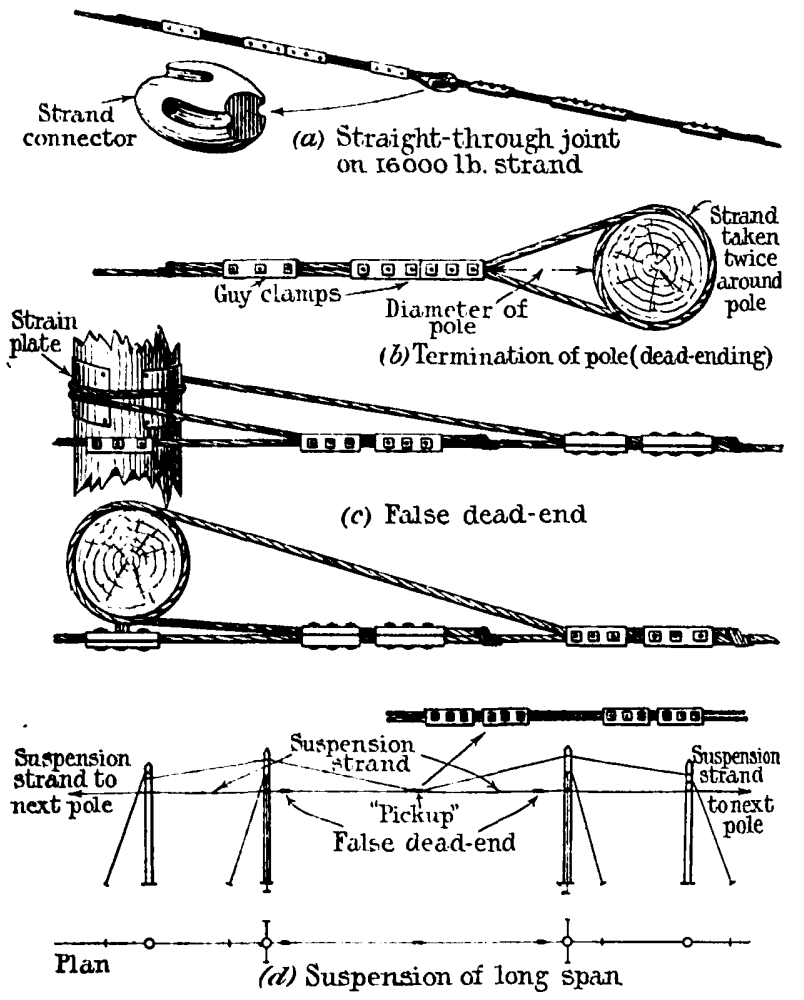

Fig. 9.-Suspension-strand jointing and terminations.

special points, such as steep gradients, crossings, pick-ups, etc. It has the effect of terminating the strand. A pick-up, in the case of a long span of cable, is shown in Fig. $9(d)$.

The universal method of securing the correct tension of the suspension strand during construction is rather ingenious. The sag of each size of cable at various temperatures after installation, but without ice or wind load, is first ascertained, and from this the permissible initial tension in the strand is determined. The construction gangs measure the tension of the strand during erection by a method of vertical oscillations. A light rope is thrown over the strand at the centre of the span, where there is no joint, and by giving the rope an up-and-down movement (a process known as "pumping") the strand also is caused to move in rhythm. By comparing the counted number of complete oscillations over a period of 15 seconds with the figures tabulated for each size of strand for varying lengths of span at different temperatures, the men can adjust the tension until the correct number of oscillations has been obtained. The author was present on one occasion when comparative tests were made by means of a dynamometer, and it was evident that the oscillations method gave a much quicker and more satisfactory result. In shorter spans a 5-lb. weight is hung from the end of the hand-line, which is slung over the suspension strand, in order to damp down the number of oscillations. Provision is made for this in the schedule supplied to the men.

In the case of exchange cables it is frequently necessary to branch off a cable in one or both directions laterally. This can be done at mid-span, where perhaps it is not possible to erect a pole, by the formation of a crossover in the suspension wire by bolting two cable suspension clamps at right angles. The $Y$ or forked joint is made at least 24 inches away from the junction, and is secured to the strand by marline ties.

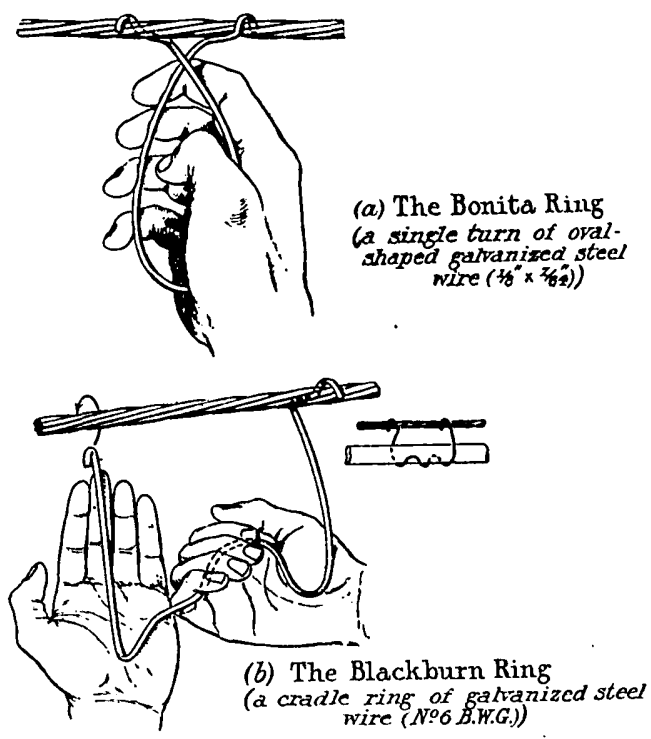

Frg. 10.-Method of fixing metal cable rings.

(c) Cable rings.-MLarline, leather, zinc, etc., for the purpose of suspending cables from the strand, have been superseded by a round-section steel ring. The two types now largely used by the telephone companics are the "Bonita" and the "Blackburn." Figs. $10(a)$ and $10(b)$ show the method by which these are fitted. In both types of ring the ends are shaped for hooking to the strand. No tool is required for attaching or removing them. The rings are placed 16 inche's apart on a $16000-1 b$. suspension strand, and 20 inches apart on a $10000-$ or $6000-1 b$. suspension strand. It the pole the rings in all cases are placed 0 inches from the cross-arm bolt on either side. In the larger size's of cable an additional ring is placed on each sicle, miclway between the first and sccond rings, i.e. $1 \pm$ inches on either side of the pole.

Prior to the erection of the cable, the rings are placed in position by a wireman who moves along the sus- 
pension strand in a " bosun" chair. A tarred hand-line or galvanized iron wire is passed through the rings as they are fitted, for the purpose of pulling the steel hauling rope.

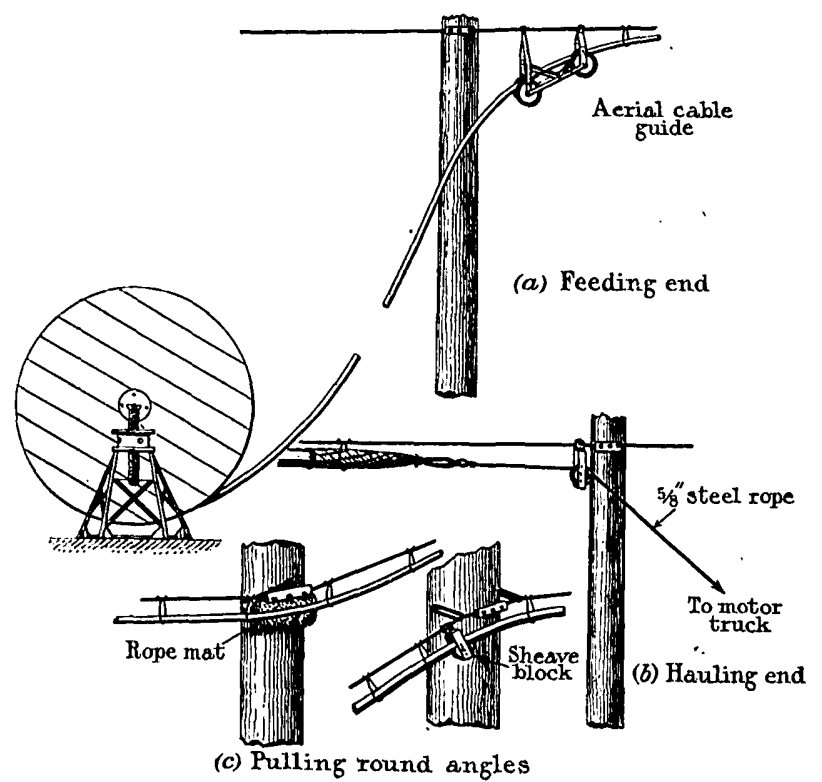

FIG. 11.-Erection of aerial cable.

(d) Erection of aerial cable.-The metal rings grip the suspension strand so tightly that they form practically an aerial conduit and do not alter their position during the installation of the cable. The cable drum is mounted on jacks about $30 \mathrm{ft}$. away from the foot

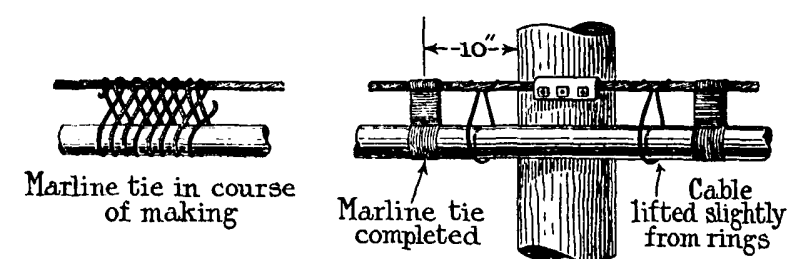

(a) Marline tie at pole (for prevention of xing cuts)

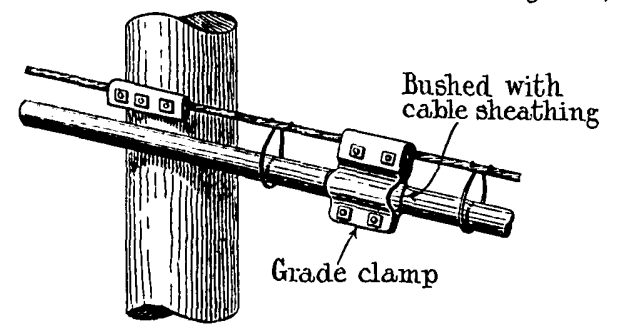

(b) Grade clamp (for prevention of "creeping")

Fic.12. - Marline tie and grade clamp for acrial cable.

of the pole, from which point the cable rises without intermediate support to the suspension strand. One end of the cable is dressed down by having two circular rings beaten in the sheath, and a wire grip is afterwards placed thereon. The $\frac{5}{8}$-inch steel hauling rope connected to the motor truck is pulled through the rings by means of the line inserted for that purpose. Usually an under- hand feed is arranged, as shown in Fig. 11. A cablerunning device, formed by a combination of two sheave blocks, is placed on the strand, $2 \mathrm{ft}$. from the pole at the feeding end. At corner poles where the strand pulls away from the pole a sheave block is used, but in the case where the strand pulls in to the pole, a rope mat is fixed to prevent abrasion of the lead sheath. On a straight run, a full-size cable of standard length (about $500 \mathrm{ft}$.) can be installed without any intermediate blocks or other gear if the cable is well lubricated before being started along the rings. For this purpose a thick motor oil is poured on the cable and then distributed by a piece of burlap, or oil is applied by means of a syringe.

(e) Ties and grade clamps.-For the purpose of preventing ring cuts on toll or large cables (from which

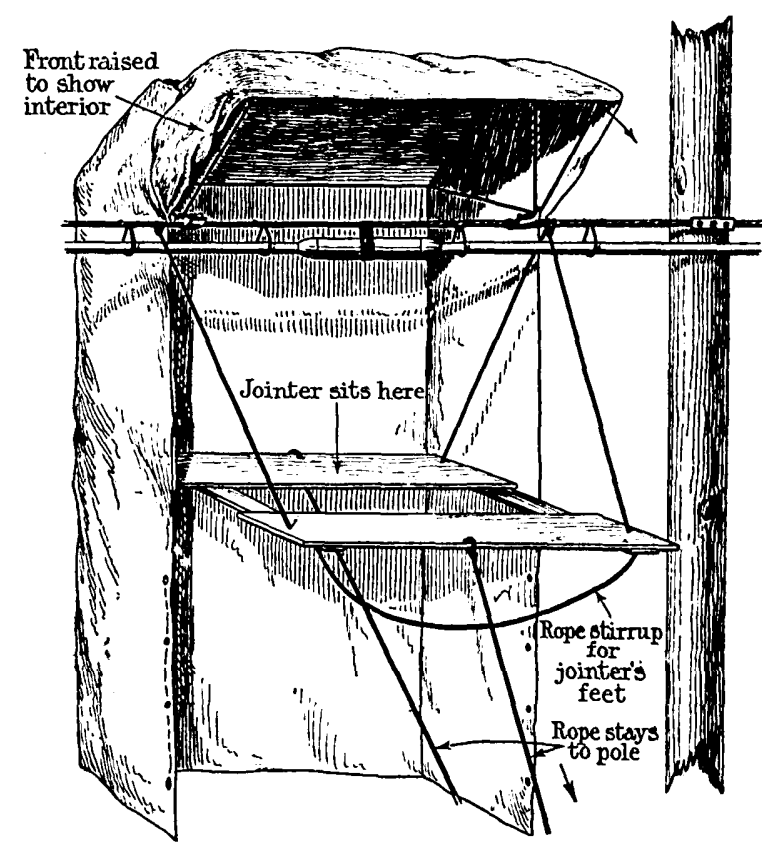

FIr. 13.-Platform and shelter for jointers on aerial cable.

there is little or no local distribution) a marline tic, as shown in Fig. $12(a)$ is used on either side of the pole as a support. To some extent this is a temporary expedient, as experiments with special types of rings for installation at the poles seem to have more satisfactorily solved the problem. On gradients the cable is clamped to the strand by means of a marline tie or a metal grade clamp. The latter type of clamp is shown in Fig. $12(b)$. A tie or clamp is fixed at the highest pole on the grade, after which its frequency (i.e. on every pole, or every second, third, or fourth pole) depencts upon the steepness of the gradient. As the cable is rigidly fastened to its suspension strand, the tic or clamp prevents it moving along the rings after erection.

(f) Cable jointing.-Particulars of jointing operations will not be mentioned here, as details are given under Section V (4). The only exceptional feature in acrial cable work is the type of platform and jointers' shelter which has been devised (see Fig. 13). The platform 
consists of two halves with a space between so that the jointer can rest his legs on a rope slung from the platform. The "helper" can also sit comfortably on the platform facing his jointer, if required. During stormy weather a collapsible tent is used, having sides which extend downwards sufficiently to keep the jointer perfectly dry. Where practicable, the position of the joint is arranged to be near a pole, so that a ladder will not be necessary for stepping on to the platform. The platform can be stayed to the pole to prevent undue rocking.

(g) Bonding.- On all aerial cables the practice of bonding the cable sheath to the suspension strand is adopted at every 10th span. A piece of lead strip or tinned copper ribbon is soldered to the cable and inserted between the two halves of a guy clamp, which is secured to the strand.

(h) Terminations.-In the case of an underground "dip" (i.e. where it is necessary to take an aerial

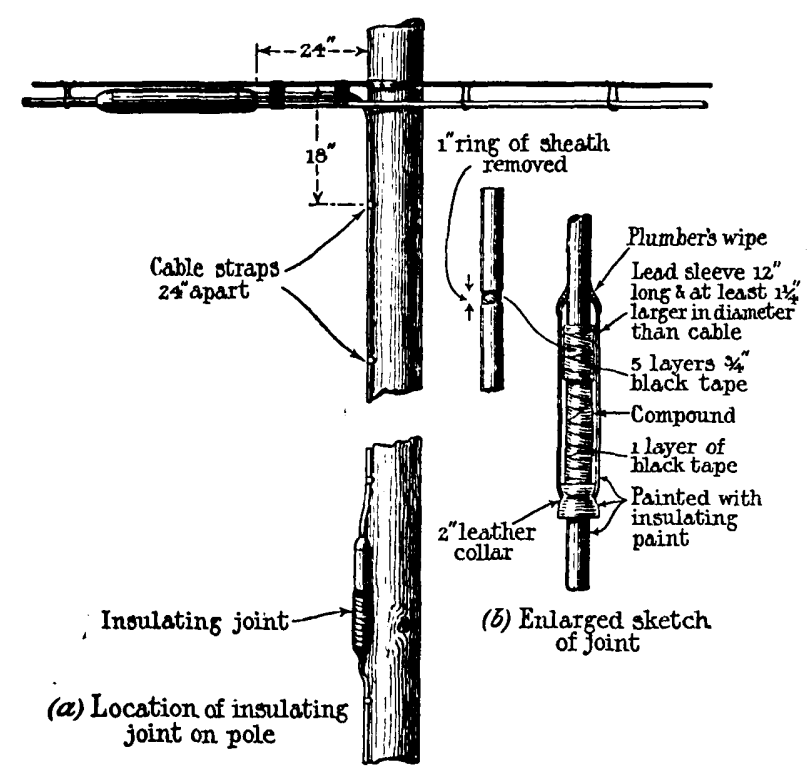

FIG. 14.- Insulating joint between aerial and underground cable.

cable through an underground duct for a special crossing) it is unneriessary to terminate the cable at the two ends. Where, however, aerial cable is to be connected with upderground cable, a terminal box fitted with sealing chambers, fanning strips and fuses, is used. These boxes are manufactured in standard sizes and the dry core paper cable is connected to the terminal posts in sealing chambers.

To break the electrical continuity of the cable sheath and thus prevent the flow of current along the sheath in the underground section where there is no cable terminal fitted, what is known as an "insulating" joint is made at some convenient point on the pole before the aerial cable is connected with the underground cable. An external type of insulating joint is shown in Fig. 14. A l-inch ring of sheath is cut away, and five layers of tape are placed over this point, extending 1 inch over the sheath on either side; one layer of tape is also continued over the sheath on one side for a distance of about 12 inches. A lead sleeve is beaten down at one end over a few layers of rubber tape and a 2-inch leather collar; the sleeve is filled with compound, and the other end closed by a plumber's wipe.

Where an exchange cable is terminated externally for distribution purposes the terminal almost invariably used is known as the "No 14 type." Details and also a sketch of this type of terminal were given by Mr. F. G. C. Baldwin in his paper "Some Considerations in the Manipulation of Dry-Core Telephone Cables " before this Institution.* It consists essentially of two elements, a galvanized cast-iron box and a porcelain block for mounting lock-nut terminals; 6 - $\mathrm{ft}$. or 9 -ft. lengths of dry-core cable-fitted at either end as desired-are fanned out on the back of the terminal posts, the back being filled in solid with compound. The terminals are made in standard sizes, 11,16 , and 26 pairs. In order to connect them to the distribution cable it is

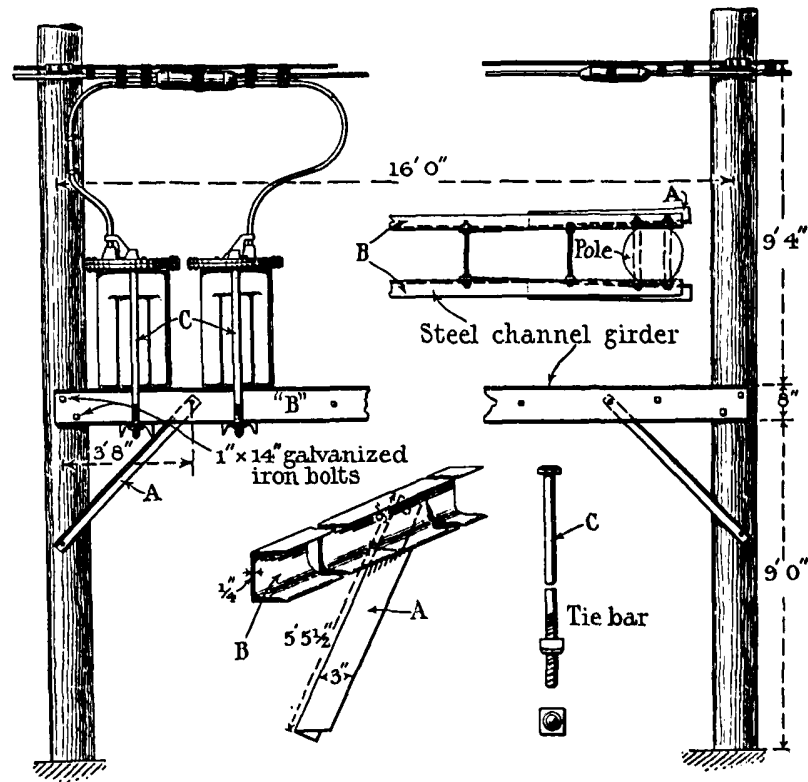

FIG. 15.-H-pole fixture for carrying loading-coil cases.

necessary only to make a straight joint on to the end of the stub cable with which they are supplied.

An alternative cable terminal which is used to a limited extent in some parts of the United States is known as the "No. 8." This type is enclosed by a circular tin top, but, although it represents a satisfactory cable terminal in many respects, the No. 14 type is usually preferred.

(i) Loading coils.-For aerial cable loading the pot may be mounted on a pole, or placed in a manhole at the foot of the pole, or buried in the ground close to the pole. In the second and third cases an insulating joint is required. Wherever possible the first method is adopted, as much shorter stub cables are then required. A single spindle pot is attached to the pole by means of brackets; for multi-spindle types a small platform is erected on the pole. A full-size toll cable, to load which completely will probably require five or six pots,

* Journal I.E.E., 1909, vol. 43, p. 643. 
necessitates the erection of a special $H$ structure. This consists of two poles erected about $16 \mathrm{ft}$. apart in line with the route. A steel girder (channel) is erected between the poles, the whole structure being suitably braced and supported for carrying the pots, as shown in Fig. 15. The complete structure provides an inexpensive and thoroughly stable means of accommodating the loading equipment for aerial cables.

(j) Advantages claimed for aerial cable construstion.The advantages of an aerial cable system for distribution purposes, due to its flexibility, are mentioned in Section IV. It is only during late years that American engineers have satisfied themselves that the practice of erecting toll cables aerially is economical where the ultimate number of full-size cables will not exceed, say, two. Each case is, of course, considered on its merits. In sections through towns an underground "dip" is invariably made, use being made of a spare duct included in the local telephone system. The advantages claimed for aerial toll cable are briefly as follows :-

(1) The initial investment for aerial cable in place is less than for similar cable placed underground, where both pole route and underground route have to be specially constructed. There is also a saving on the annual cost of aerial cable.

(2) Where the ultimate traffic is uncertain, there is less risk in the smaller investment. This applies also to the factor of obsolescence, which cannot be overlooked.

(3) The work of installation can be completed much more rapidly, and consequently there is an earlier return on the investment and an earlier service for the public.

(4) Aerial cable may be erected over rocky or mountainous country where underground construction would be impracticable.

(5) Reduction in cost and lower transmission losses may be secured by the more direct route which may frequently be followed aerially.

(6) River and canal crossings can be negotiated more easily by aerial than by submarine cable, provided the crossings are relatively short.

(7) Although there is a greater possibility of faults with aerial cable, repairs can be effected more readily. The cable is accessible at all points, without the necessity for withdrawing a section: service is therefore quickly restored. Further, underground cable is more liable to total breakdown from the flooding of ducts or manholes, due to defects in plumbing and other causes, than is aerial cablc.

(8) Aerial cable is always open to inspection, and breakdowns due to street operations are avoided. Also, when roadways are being re-made, raised, or lowered, an aerial cable route may easily be diverted.

(9) There is practically no risk of electrolysis.

(10) During winter, underground cable is liable to be crushed within the ducts by the freezing of water. Aerial cable is exposed to no such danger.
The chief drawbacks to the use of aerial cable are :-

(1) The line may be objected to on æsthetic grounds. If, however, the construction work is carried out in a proper manner, a pole route carrying cable only is perhaps less objectionable than a heavy route of open wires.

(2) Ring cuts and also crystallization of the lead sheath (due to expansion and contraction of the cables) may occur. These serious drawbacks have now been overcome to a large extent.

(3) Injuries caused by gun-shot, malicious damage, linesmen's spurs, beetles and squirrels, and so on, have been mentioned as material risks, but in practice there have been very few breakdowns due to any of these causes.

(4) On account of the prevalence of wood buildings there is a possibility of damage to aerial cable by fire. This danger is minimized by skirting the villages and by underground "dips" through towns.

(5) Damage caused by blizzards to pole routes carying open wires engendered expectations of similar experiences with aerial cable, but during the past few years it has been demonstrated that where only cables are carried the route is practically immune from storm damage. In fact, the calculated strength of a new route of class A chestnut poles carrying two full-size cables is such that with $1 \frac{1}{2}$ inches of ice on the suspension strands and cables, and a 70 m.p.h. wind velocity, there is a factor of safety of 4.7. It is calculated that after 19 years' life, with a loss of $\frac{1}{2}$ inch per year in the circumference of the pole, there is still a factor of safety of $2 \cdot 0$ under similar conditions.

In general it is claimed that the stability of an aerial cable route is assured by the precautions taken during installation. The chief points to be observed in planning such a route are: Short spans, extra stout short poles, removal of trees immediately adjacent to route, suspension strand at correct tension, the right class of ring at short, equal distances apart, marline ties to prevent crystallization and ring cuts, and grade clamps to avoid creeping. By the adoption of these measures many of the past weaknesses of aerial cable have been eliminated.

\section{(3) Conduit Routes.}

(a) Types of conduit.

(i) Vitrified clay.-The type of conduit very largely used by the telephone companies is made of a particular clay which has been highly vitrified. Single-way ducts are circular in bore, and multiple-way ducts are square with the corners slightly rounded off. The multiple duct is made in various sizes up to 9 ways, as shown in Fig. 16. Conduits with l.ss than 4 ways are seldom installed, aerial cable being adopted, if conditions permit, where only one or two cables are involved. Various combinations of the standard sizes are made to obtain a larger number of ways, when required. All joints are staggered, both horizontally and vertically. 
It is necessary to butt the ends together, two steel dowel pins being used at each joint to maintain alignment. Joints are wrapped with single thicknesses of a 9 -inch strip of wet muslin plastered with $\frac{1}{2}$ inch of cement mortar.

Multiple-way concluits are laid on a 4-inch concrete foundation, and in towns a top cover of concrete is frequently given as a mechanical protection. In city work, and where the sub-soil is marshy, concrete is sometimes used at the sides of the conduit, so that, together with the foundation and top protection, a complete envelope of concrete is formed round the duct line. It is recognized that such a liberal use of concrete adds considerably to the installation cost, but engineers consider it is a justifiable insurance against external

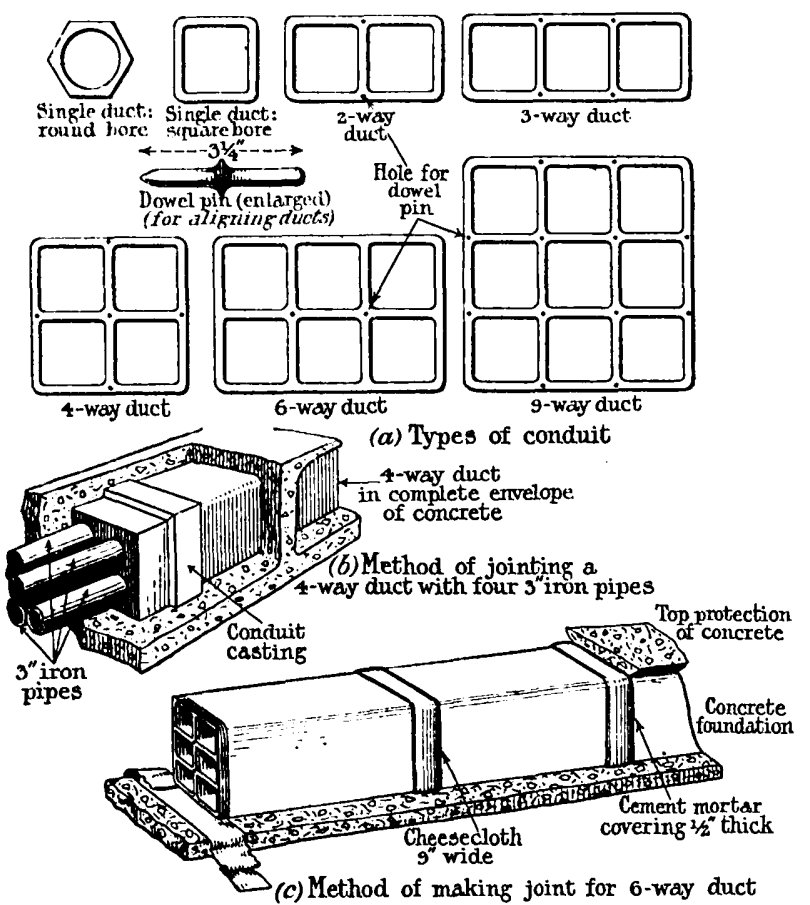

Fig. 16.-Types of conduit and methods of jointing.

injury. Experiments are at present being made to ascertain whether self-aligning ducts, fitted with spigot and socket joints, as used in this country and laid without concrete, are likel; to be damaged when laid at normal depths.

At the time the conduit is laid a No. 12 B.W.G. $(165 \mathrm{lb}$.) galvanized iron wire is drawn into one of the ducts to be used, for pulling in the steel hauling rope. The remainder of the ducts are rodded and wired as required.

(ii) Creosoted wood.-A single duct of creosoted yellow pine (known as "pump log ") $4 \frac{1}{2}$ inches square on the outside and with a circular hole 3 inches in diameter, is also largely used. Lengths of creosoted wood duct vary from $3 \mathrm{ft}$. to $10 \mathrm{ft}$., including the tenon at one end and the mortise at the other, provided for jointing purposes. The two ends fit into one another, no nails, screws, or compound being necessary. Creosoted wood is used for both small and large runs where the cost of the wood is relatively low. Generally speaking, if more than 4 or 6 ways are required, vitrified clay is found to be the more satisfactory. It is common practice to provide an additional duct as a crown to a main conduit line, for the accommodation of future lateral connections. Creosoted wood duct is very suitable for this purpose, as it can be cut into at any point without interference with the main route.

(iii) Iron or steel.-Metal conduits are employed only for the lateral or " riser" at distribution points or where their use is unavoidable in negotiating obstructions. An iron connecting piece is used to link up steel pipes with vitrified clay conduits where a manhole is not required.

(iv) Other classes of conduit.-Fibre tubing has been used to a limited extent, but it is considered that as an alternative duct for telephone work fibre is not so satisfactory as the standard types previously mentioned. Concrete ducts were installed several years ago by some of the telephone companies but were not successful, on account both of the increased friction during the

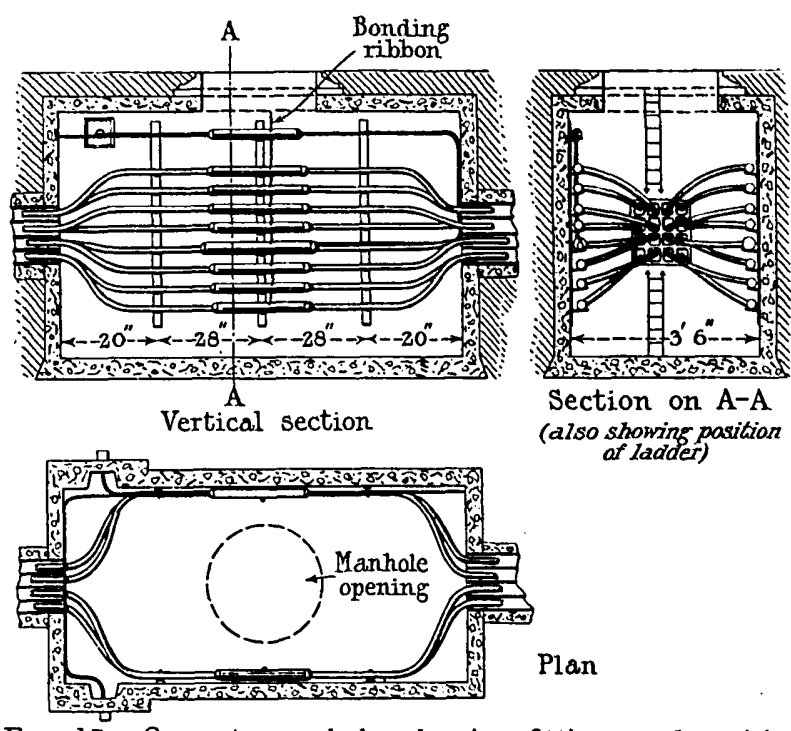

FIG. 17.-Concrete manho!e, showing fittings and position of cables.

installation of the cable and of the deleterious alkaline effect on the lead sheath.

(b) Manholes.-Manholes were formerly constructed in brick but are now more frequently of concrete. The roof portion is reinforced with $6000-1 b$. steel strand. Construction of concrete manholes is facilitated by the use of portable templates, made in such standard sizes that they may be braced together to serve for any size of manhole required. The manhole frame and cover are so arranged that entry is made in the centre of the manhole. In town work every manhole which is frcquently used is provided with a small galvanized. iron ladder hooked to the framework of the opening. Construction gangs carry a similar type of ladder for use in entering manholes not so provided. Racks for the support of cables around manholes are always fitted to the side walls during the construction of the manhole. Hangers (cable rack hooks) are not fixed until the cables are installed. The general arrangement of a typical manhole is shown in Fig. 17. This figure also shows 
the way in which the cables are taken round the walls. The joints are alternately staggered where it is not possible to centre-rack, as indicated. Distribution pipes are terminated in a small pocket on either side, to

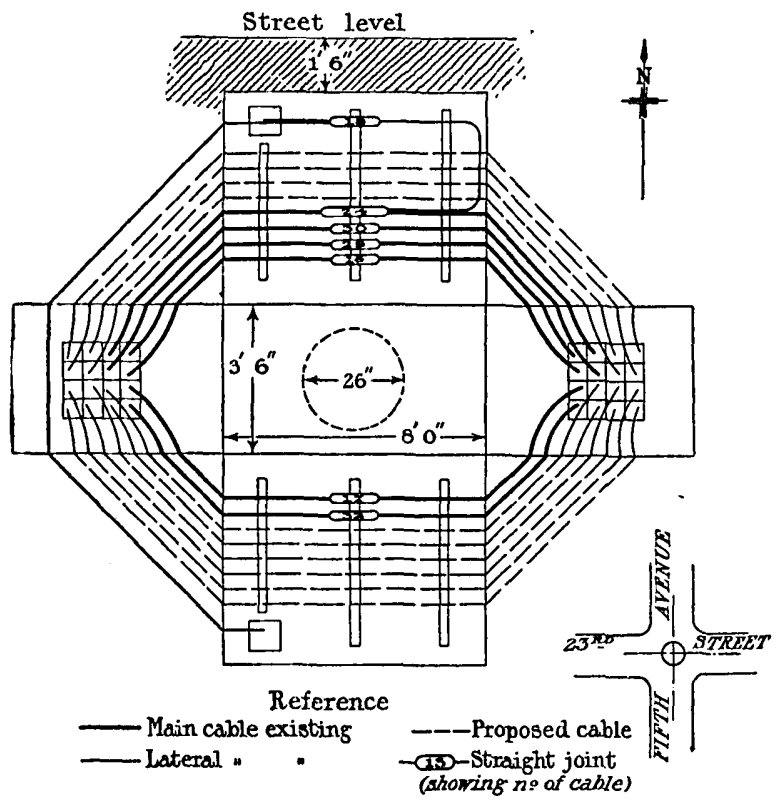

Fig. 18.-Example of cable manhole record.

prevent the cable from becoming kinked at the point where it enters the pipe.

A diagrammatic sketch (see Fig. 18) is made, as an

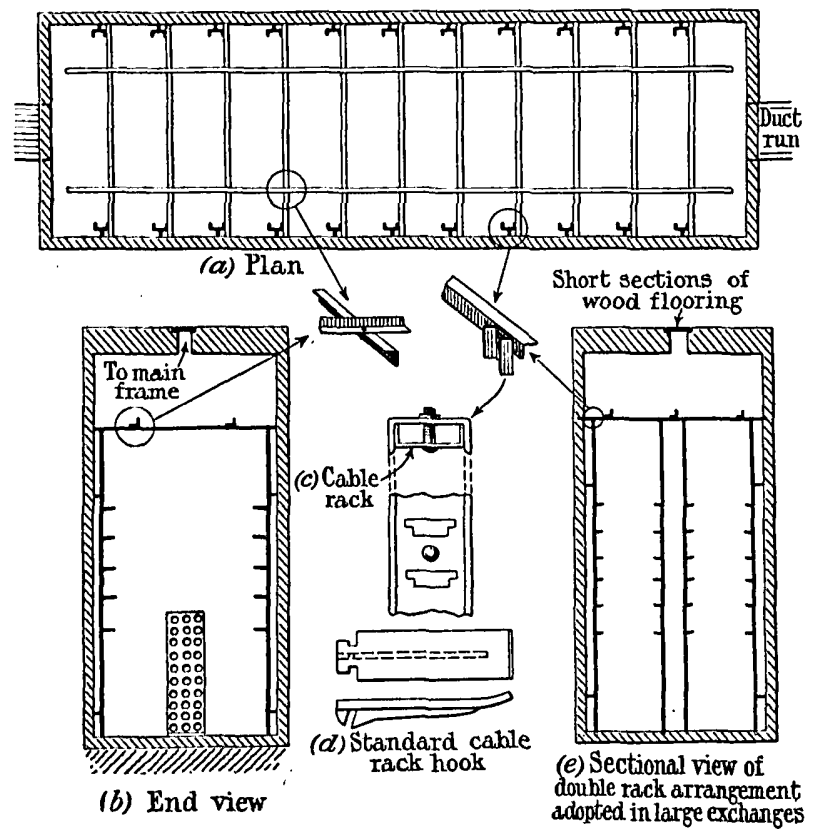

FIG. 19.-Cable vault at exchange.

office record, of each manhole at the time of its construction. The cables which are proposed in plans for future growth are indicated on manhole records by dotted lines, so that no error is made when the various ducts are assigned for new cables. By the exercise of foresight in planning manhole sizes for the ultimate cabling, and by utilizing the walls solely for carrying racks and cables, there is not the congestion in manholes which might be expected in the heaviest parts of New York, where as many as 70 or 80 cables are accommodated.

The standard size of manhole used for the accommodation of loading coils is $17 \mathrm{ft}$. long by $8 \mathrm{ft}$. wide and $7 \mathrm{ft}$. deep. In special cases manholes are from 35 to $40 \mathrm{ft}$. in length. In the longer ones two or even three covers are fitted with means for lighting and ventilation. If local conditions permit, double-deck manholes aro constructed in which the loading-coil pots are accommodated below an iron grating, which constitutes a mezzanine floor.

(c) Cable vault at exchanges. $-\Lambda$ the point of entry to an exchange the conduits are terminated at the building line, and from this point cables and joints are supported by a system of racks and hangers. The arrangement is a repetition of the method used for the support of cables in manholes, and provides a very flexible system. Fig. 19 (a) shows one method of leading-in, suitable for exchanges to take up to 10000 lines.

Where cables for two or more 10000 -line unit switchboards must be accommodated in the same vault, a double (or even treble) tier of racks is constructed down the centre of the room as shown in Fig. $19(e)$. The leading-in arrangement there given appears to form an excellent solution to a problem which has excrcised the minds of telephone engineers for many years.

(4) Underground Cables.

(a) Installation of cable in ducts.-A motor truck fitted with a power-driven winch is used by the telephone companies for the installation of underground cables. It is described more fully in Section VII. The temporary arrangement of gear at the hauling manhole is as shown in Fig. 20. The fixing of the gear and the hauling operations are simplified by the fact, previously mentioned, that in practically all cases the manhole opening is situated over the centre of the manhole. Complicated gear varying with different manholes is thereby avoided. As cables in manholes are all supported from racks fixed to the side walls, they offer no obstruction to cable-drawing operations or the associated gear. In order to avoid moving the truck to each successive manhole, drums of cable are delivered in pairs at alternate manholes. A further advantage derived from this method of working is that the jacks, spindle, etc., available at one point serve for two drums of cable. For country work the gear is conveyed from one manhole to another by means of a small box van, which is also used for drawing out the galvanized iron wire which hauls in the $\frac{5}{8}$-inch stecl wire rope. The back wheel of the van is jacked up, and when the engine is started the rotation of a small drum clamped to the spokes of the near wheel withdraws the wire from the conduit and coils it up.

In city work a small petrol-driven engine is used for drawing out the galvanized iron wire in the two directions. A woven-wire grip is placed on the end of the cable after it has been dressed down for pulling in. If 
circumstances indicate that hauling is likely to be heavy the grip is reinforced about half-way along its length by a short section of galvanized iron wire, wrapped basket-fashion in and out and beyond the grip along the cable for a distance of 6 inches. The

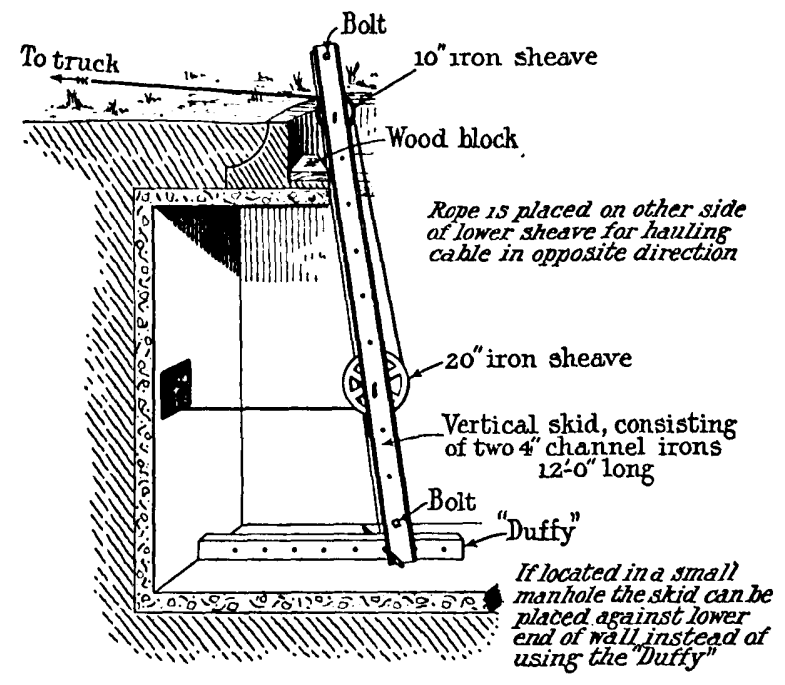

FIG. 20.- "Rigging-up" in manhole.

adoption of this precaution ensures the wire grip being firmly attached to the cable. and prevents any possibility of the cable end being pulled off, or the lead stretching.

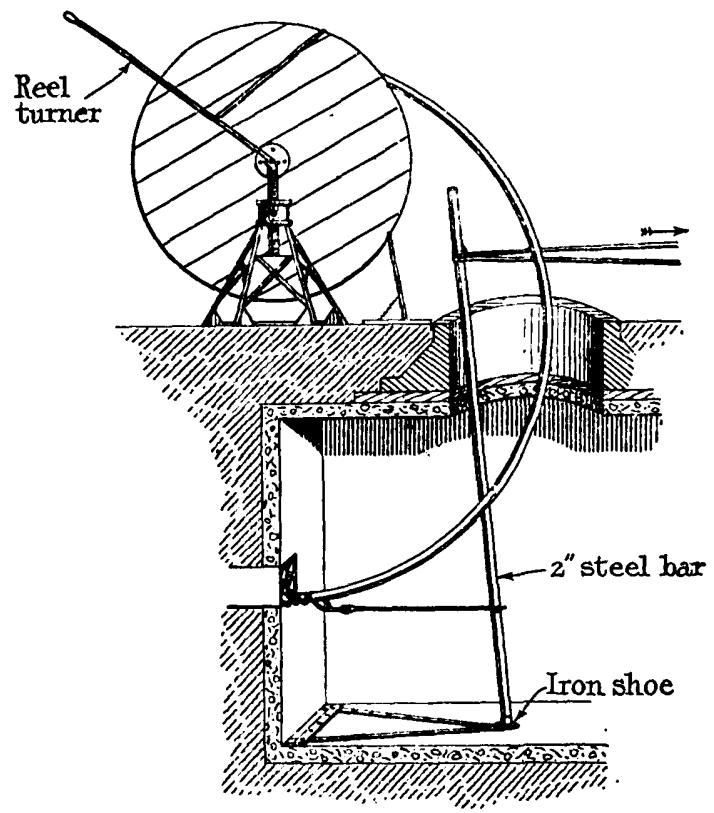

Fig. 21.-Withdrawal of cable; pumping-out method.

A thick motor oil or a graphite grease is used as a lubricant for the cable during installation. American engineers consider that no kind of lubricant forms an effective preservative against chemical or electrolytic action on the lead sheath.
Before the cable placers leave a manhole, the cable ends are tied to hooks fitted in the cable racks, and metal duct shields are inserted under the cable at the mouth of the duct. Men employed in cable installation are carefully drilled in particular operations, and they co-operate so well that, with the aid of the motor truck and other devices, the speed of drawing-in cable has been increased to at least five times that previously attained. The record length of cable drawn into a duct in one day under ideal country conditions is a total of 4 miles of full-size cable contained on 44 drums. In this particular case 20 men were employed for 10 hours and performed the complete work of installation, excluding the delivery of cable to the site and the collection of empty drums.

(b) Withdrawal of cable.-If a motor truck is used to pull out cable, the wire rope is passed over the sheaves, as for pulling in. A double-ended wire grip, servage of soft marline or unstranded manilla rope, is used as a grip. The extent of each motion is regulated by the

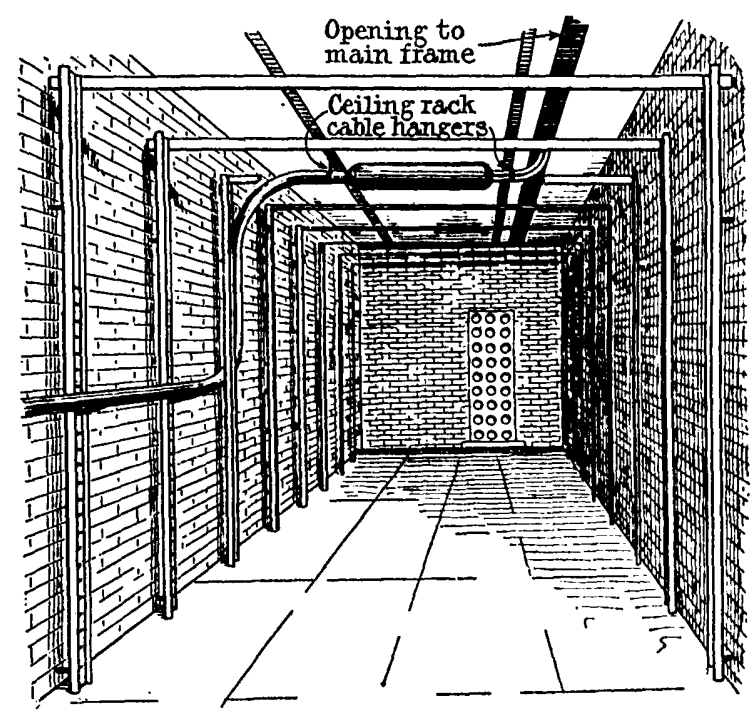

FIG. 22.-Installation of cable in cable vault.

distance between the lower sheave and the end of the duct, the grip being pushed back by hand at each pull. This operation is known as "luffing." When cable is pulled out by hand, the "pumping-out" method shown in Fig. 21 is adopted. It is a very quick and effective process if the man slipping back the grip and those giving attention at the rope and drum work in unison.

(c) Installation of cable at exchange.-The general lay-out of cables in the exchange cable vault is shown in Fig. 19. If the main frame is situated on the ground floor of the building, the joint between the underground dry-core cable and the terminating cable (known as the "tip ") is made in the cable vault in the basement. In such circumstances a long opening, extending the full length of, and immediately beneath, the main frame is provided in the floor, and through this gap the terminating cables are led direct to the main frame equipment. The underground cable is continued along hangers fitted in the racks to a point adjacent to 
where it will be terminated. The cable is taken up the wall in supporting clips to the point where it is left for the jointer.

Fig. 22 shows a cable with its joint in position. The space between the racks and wall is sufficient to allow cables to be taken from the hangers of one rack and up the wall to the tie bars or ceiling racks without fouling the run of other cables. Hangers can be supplied to carry two or three cables, as may be required. If the main frame is accommodated above the ground floor, the joint between the underground cable and its terminating cables is situated in a suitable trench immediately behind the main frame; with this arrangement the underground cable is extended beyond the vault through a duct in the vertical wall of the building to the point required. A length of $6000-1 b$. suspension

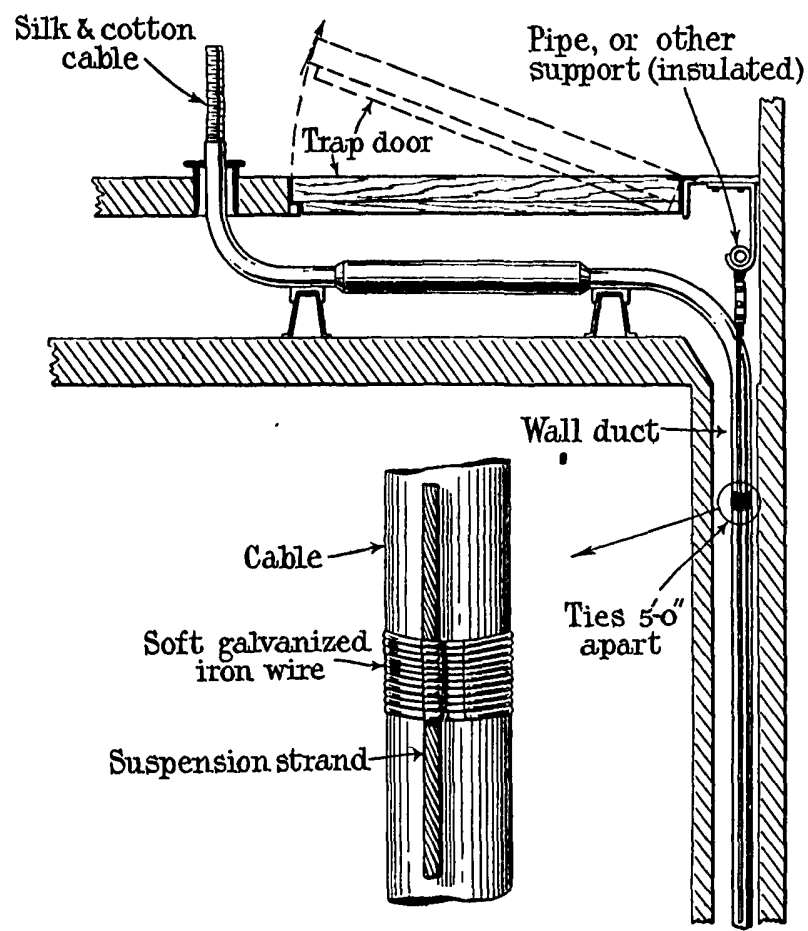

Firg. 23.-Support of cable in vertical pipe and type of joint at back of main frame.

strand is used to support the cable in the vertical duct. The upper end of the strand is terminated on the framework of the building, or on a suitable support installed for the purpose. If the framework of the building be used, the suspension strand is electrically insulated therefrom.

The strands of the suspension wire are forced apart by means of a steel punch, and several turns of No. 18 I3.W.G. galvanized soft iron wire are passed between the strands and round the cable. A cable with its supporting strand is either lowered from the main frame floor or pulled upwards from the cable vault, according to local conditions. Fig. 23 shows the upper end of the cable, and a completed tie. When the main frame is located on one of the higher floors of a large building, it is often necessary to take cables through as many as 20 or more floors. Without some suitable VOL. 60 . method of supporting cables, such as the one described the weight would impose a serious strain on the lead sheath.

(d) Preliminary work for jointing cables.-After setting the cables in position for jointing, and removing the lead sheath for the required distance, a piece of cotton tape freshly boiled-out in paraffin wax is wrapped tightly round the core at the edge of the sheath. The tape is worked back between the sheath and the core for about $\frac{1}{2}$ inch, in order to prevent the paper insulation being cut at the point of subsequent bending.

(e) Boiling-out cable ends and joints.-Before wire jointing is commenced the bared ends of all telephone dry-core cables are boiled-out with paraffin wax at a temperature of about $375^{\circ} \mathrm{F}$. The object in view is to preclude absorption by the paper insulation of moisture from the atmosphere, from the jointers' hands, or from any other source. The apparatus used for the boiling-

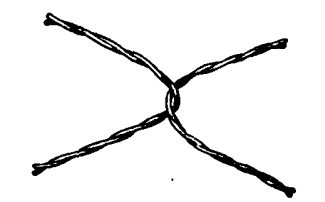

$1^{\text {st }}$ operation-Marking of paper

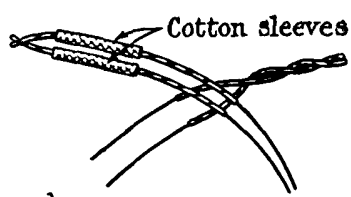

$2^{\text {nd }}$ operation-Paper skinned \& cottan sleeves slipped over
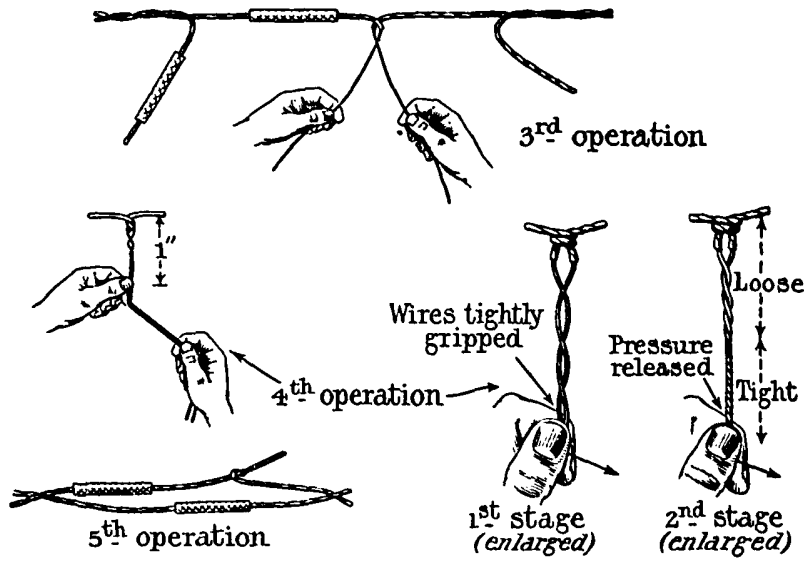

FIG. 24.-Method of making twisted wire joint on small conductors.

out of cables consists of a 4-gallon steel kettle, a ladle, a drip pan, and a paraffin furnace. Molten wax is ladled from the kettle and poured over the end of the cable or joint, and the surplus is received in the drip pan which is suspended directly beneath. A small hole is provided near the rim at one corner of the drip pan to allow the wax to be easily poured into the kettle.

It is specified that paraffin wax must not be heated within $10 \mathrm{ft}$. of any manhole. This precaution is taken on account of the possible presence of explosive gas. The operation of waxing has never been considered to be at all hazardous if reasonable precautions are taken when carrying the pot from furnace to manhole and lowering it to the jointer. There have been very few cases of injury from this cause. Upon completion of jointing, boiling-out is again performed in order to expel moisture from the joint before plumbing is com- 
menced. The specified minimum insulation is 500 megohms per mile, but by the process of boiling-out the insulation obtained in practice is usually much in excess of this figure. The materials required in the process of jointing-cotton tape, muslin and cotton sleeving-are also boiled-out in heated paraffin wax before being used.

( $f$ ) Wire jointing.-A twisted joint is made on conductors up to and including No. 14 B. \& S. (65 lb.). For larger conductors, a soldered copper sleeve joint is used. The twisted joints are not soldered in cables for exchange subscribers, but soldering is considered necessary for toll cable circuits in order to avoid any possibility of resistance unbalance which may adversely affect the transmission efficiency of the circuit. The "crankhandle " method of twisting is adopted by all jointers ; it is much quicker ; there is less chance of the formation of high-resistance joints ; and it is also less fatiguing to the men than the finger-twist method. Successive operations in the process of making joints by this method cable or the branch cable to which it is connected are separated and insulated until required, an arrangement usually referred to as a "butt" splice.

Cotton sleeves for insulating wire joints are used in preference to paper sleeves, as it is considered they are not so liable to char during the boiling-out process. They can be boiled-out several times without injury; the joint may be bound in closer; and in trunk cablo work it is not necessary to tie the four sleeves of a quad on either side to prevent their displacement during subsequent movement. The cotton sleeves are woven, and after they have been boiled-out a brass sleevcpunch is used to render them cylindrical. When they have been placed in position over a wire joint they are stretched and at the same time flattened at the ends by the thumb and finger of each hand, so that the sleeve grips the paper insulation. After the joint has been made and boiled-out it is bound with 4 -inch muslin strip preparatory to plumbing. The muslin is more quickly applied than 2-inch linen tape, and is cheaper.

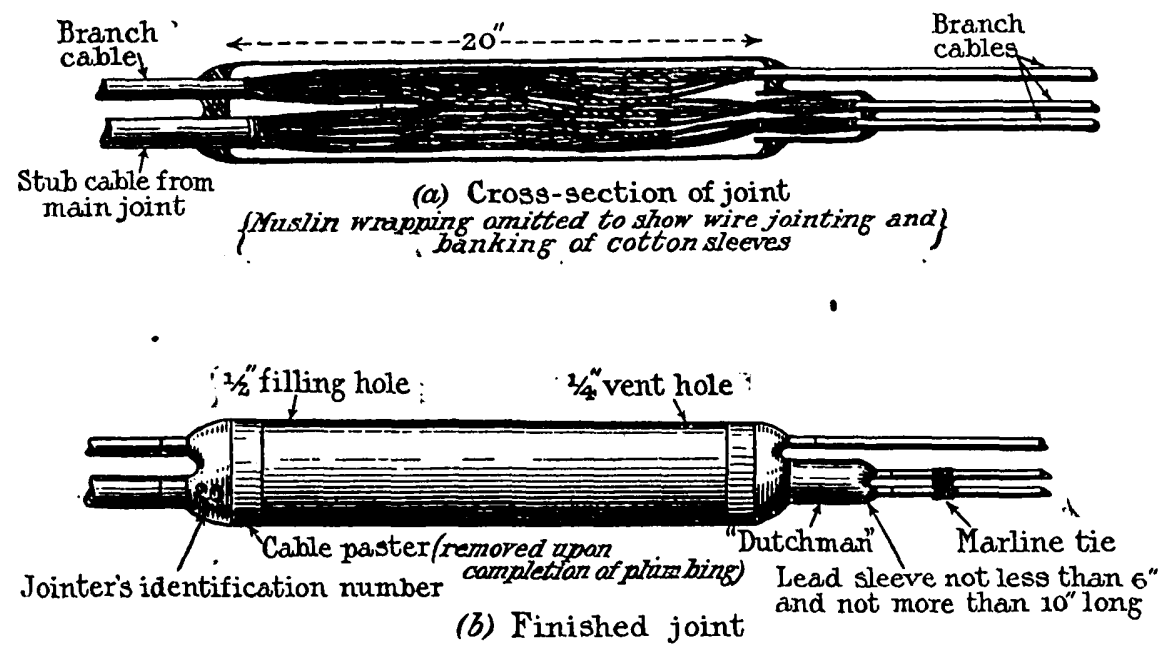

Fig. 25.-Method of making stub cable joint.

are shown in Fig. 24. There is no possibility of breaking off the wires at the neck if the twist be run in from the fingers of the left hand. The close twisting necessary to avoid high resistances is at the pigtail end, whilst at the neck the wires are comparatively loosely twisted. It should be mentioned that this crank-handle joint is not the same type of joint as that formerly known in this country as the " organ-barrel " twist. In the latter method of jointing, the wires are grasped at the neck and, consequently, there is a danger of the wire being broken at this point; it is, therefore, a dangerous type of joint to make, particularly with the small gauges of copper wire now in vogue. Jointers use scissors during jointing operations, as they are more easily handled than pliers.

When making a stub joint the wires from the two main cables and the wire of the stub cable are twisted together in one joint, known as a "bridge" splice. The stub cable is taken from the main joint to an adjoining rack, where it is then available for distribution to the branch cables. Wires at the end of the stub (g) Plumbing.-As all the jointers are fully-qualified plumbers they are able to proceed with the plumbing work as soon as jointing is completed. The cleaned portion of the lead sleeve and sheath is covered with stearine in order to keep the scraped surface bright and clean. Stearine also acts as a flux for plumbers' metal. Cable pasters are used in preference to plumbers' "soil" for limiting the extent of the wipe at the end of a lead sleeve. Complicated plumbing is usually avoided in main joints by the use of stub cables, as shown in Fig. 25.

The maximum length of lead sleeve used on any size of joint is 20 inches. In general, the maximum number of cables entering a wipe is two. If three cables have to be connected at the same place, what is known as a "dutchman" is made ; that is, a short piece of lead sleeve is interposed, into which two cables can be taken. It is considered that, if more than two cables are taken into the same wipe, there is a possibility of the joint breaking down. Moreover, a blow-lamp would be required, and a jointer's tool-kit does not include this 
item, on account of the danger of using a naked light in a manhole. For the same reason, electric lamps in conjunction with portable accumulators are used for the illumination of manholes.

As an additional safeguard against the rapid penetration of moisture into a $Y$ joint the latter is filled with paraffin wax. After the wipes have set, but before the sleeve has cooled, a small hole is made at each end of the sleeve, one being used as a filling hole and the other as a vent. Heated wax is poured in until the joint is full. Straight joints are not filled with paraffin wax. The jointer stamps one of the wipes with his code number, and ties on to the cable a small brass disc bearing the number which has been assigned to it. Upon the completion of plumbing work cables are dressed into their final position on the walls, where they remain undisturbed.

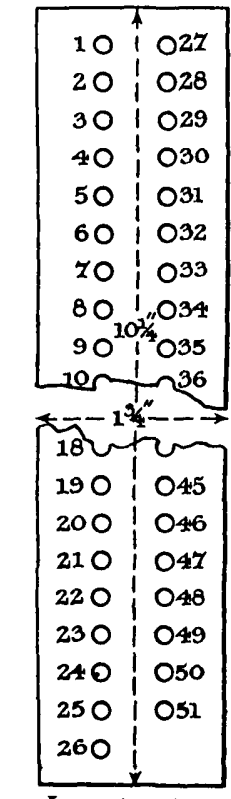

(a) Linen test board

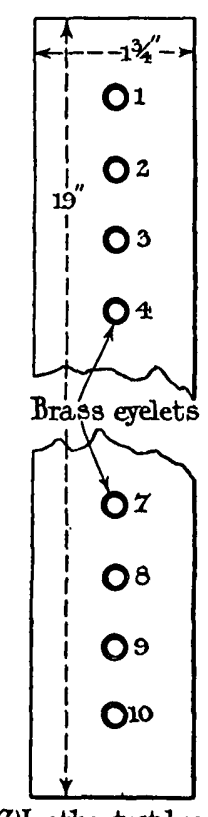

b) Ieather test board
for quadded calles

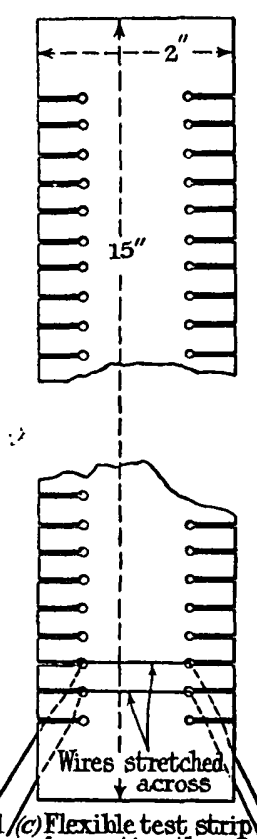

for section throws
FIG. 26.-Jointers' test-boards.

(h) Speed of jointing.-By the adoption of the various devices mentioned in the foregoing paragraphs the jointers are able to work at a rate of over 100 pairs an hour on a subscribers' cable. The more experienced men can joint as many as 150 pairs an hour, with the result that it is often possible to complete a 600 -pair, 10-1b. cable joint in an 8-hour day.

(i) Bonding.-Owing to the trouble caused by electrolysis, all cables in manholes or jointing chambers are bonded together by means of tinned copper ribbon. It is not customary, however, to sink earth plates under the floors of manholes, as experience has shown that connections made by bonding ribbon between the earth plates and cable is not reliable. Periodical tests of leakage current between cable sheath and earth are made. If certain limits are exceeded immediate steps are taken to localize the trouble and apply a remedy. (j) Numbering and testing.-For tagging-out conductors in an exchange subscribers' cable when making test-joints, or for numbering-through purposes, a "linen test-board" [see Fig. $26(a)$ ] is used, in preference to a numbered paper sleeve.

In re-numbering cable pairs, e.g. in connection with an exchange transfer, this board is very useful, as the stamped number can be considered as the old number, and the new number can be written on the reverse side, thus avoiding confusion between the two.

When working on a quadded cable a leather board is used. After the quads have been placed through the holes the pairs are separated. As there is no means of distinguishing between the " $a$ " and " $b$ " wires one of the wires is cut three inches shorter than the other. The wires are then referred to as "long " and "short." and recorded on the testing sheets as $L$ and $S$. When testing a large working cable of small-gauge conductors in connection with a section throw (change-over), a flexible leather strip is used, as shown in Fig. $26(c)$. Current is applied to one of the wires at the distant end, and this is picked up very quickly at the strip by running the testing lead over the exposed wire.

( $k$ ) Jointing-in loading coils.-If loading coils are installed immediately below the cables, either by being embedded in the ground or placed under the mezzanine floor of a double-deck manhole, the stubs from the loading coils may be taken direct into the main joints. Only one stub per pot is provided, and wherever possible

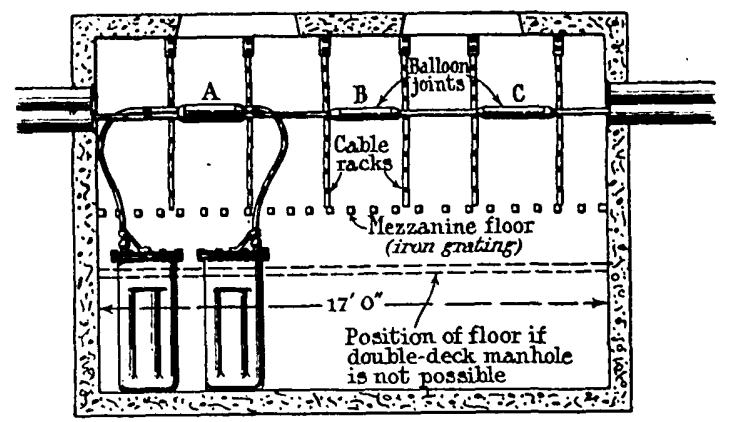

Fig. 27.--Installation of loading coils in double-deck manhole.

not more than two stubs are taken into the same joint. Where all the pots are not installed initially, a so-called "balloon" joint is made at the points where the later loading-coil stubs will be connected to the main cable. In Fig. 27 two loading-coil stub cables are shown connected up at the joint $A$, whereas $B$ and $C$ are " balloon" joints.

The method of making a "balloon" joint is as follows: Before the joint $A$ is made two 20-inch lead sleeves are slipped over the cable sheath, and a 12-inch ring of sheath is removed at the points $B$ and $C$. The wires thus exposed are doubled back over themselves so that there is about 6 inches of slack in the conductor at each point. The lead sleeves are drawn over, and wiped joints are made until such time as the additional loading coils are installed. By making the "balloon" joint, slack will then be available for jointing-in the stubs subsequently, without having to piece out the 
whole of the wires. Where it is not possible to install the loading coil pots in the same manhole as that in which the cables are jointed, an auxiliary loading-coil stub is provided.

(l) Pressure-testing.-In general, desiccators are not employed by telephone companies in America; but there are one or two companies which use a desiccator in conjunction with an air compressor, merely to test the integrity of the lead sheath between one jointing point and another after installation, and also to prove that the plumbers' wipes are sound. It is generally considered that the cost of making pressure-tests on subscribers' cables is not justified, as the number of failures experienced is so small. The cable sheath is assumed to be intact when it leaves the works, and every care is taken to avoid any abrasion of the sheath during installation. Every man learns the technique of plumbing in the company's training school, and must prove adept before he is employed on actual work; consequently the quality of the plumbing is remarkably good. The men take a pride in their work, and a cable failure resulting from a plumbing defect is regarded as such a reflection upon workmanship that it very seldom occurs.

In the case of long-distance cables the question of pressure-testing is somewhat different, since, if an undetected fault were to occur during installation, the expense of remedy would be considerably more than in towns, where a large maintenance staff is available. The disturbing effect on trunk service is also of greater moment. The author believes that the question of pressure-testing long-distance cables is now under consideration in America.

( $m$ ) Desiccation.-No attempt is made to remedy insulation breakdown by desiccation, either by means of dry air or by carbon-dioxide. The opinion held is that, if the initial construction work be carried out satisfactorily, there is no reason why a fault should develop between one jointing point and another, apart from the comparatively rare case of mechanical injury or chemical and electrolytic action. A breakdown from either of these causes would probably involve the complete replacement of the cable, unless the fault were of a purely local character, in which case the section could be boiled-out with paraffin wax. Cables are so carefully racked when placed in their permanent position in manholes that there is little chance of any injury to the joints.

Although the wax left in the sleeve does not constitute a solid joint, it has the effect, in the remote event of a defect occurring, of delaying the advance of water into the cable and so preventing serious damage before the fault is likely to be discovered. The boiling-out system results in a high insulation-resistance, and, if moisture does enter a joint later on, a process of re-boiling is depended upon to restore normal insulation. If water has penetrated too far for re-boiling to be effectual, the cable is replaced without further delay-an operation which is, however, seldom necessary in practice.

(n) Types of joint.-The differences between the various types of joint in use in America may be mentioned here with advantage, in order to elucidate their respective features and uses:- (i) The boiled-out joint is not solid. Wax at the temperature specified runs through the open joint like water, the practice being adopted merely to avoid low insulation. The quantity of wax remaining in the joint is very small, and the free passage of air is not impeded if a pressure-test is at any time required.

(ii) A $Y$ joint filled with wax is also not solid in the true sense of the word. Probably a sustained pressure-test could not be made, but the joint would serve as a fairly effective block to the passage of air, and, if the plumbing were defective, water would take an appreciable time to penetrate into the cable.

(iii) The pot-heads formerly used for terminating paper-insulated lead-covered cable in some of the cable terminal boxes are practically solid, as a black insulating compound is used, with the object of preventing moisture creeping along the rubber leads to the paper cable.

(iv) In submarine cable work, where paper-insulated cables are used, joints are required which will absolutely prevent moisture getting to the cable. Such joints are made on a principle entirely different from that of merely filling with compound, even under pressure, as there is always the possibility of water penetrating the cable owing to the contraction of the compound.

(o) Terminating cable.-At exchanges, paper-insulated cable for subscribers' lines is terminated by means of short lengths of double-silk and single-cotton-insulated lead-sheath cable. The conductors are of 10 -lb. tinned copper wire. Terminating cables range in size up to 600 pairs, the type chosen being dependent upon (1) the size of the cable to be terminated; (2) whether there is a mezzanine platform; and (3) the number of pairs accommodated per vertical of the main frame. Where three or four of these terminating cables have to be jointed to a main underground cable, a standard type of joint is adopted, using one or two "dutchmen " as illustrated in Fig. 25. In the termination of a toll cable double-silk and double-cotton-insulated wire in quad formation is used. Joints in exchanges for either subscribers' cables or toll cables are not filled with paraffin wax or other impregnating material.

(p) Cross-connecting points.-Throughout the Bell System the standard practice is to determine the best arrangement of distribution of wires to serve for the development period, and to joint them through direct, enclosing the joint in a lead sleeve. If construction work is ably carried out in the first instance there is little likelihood of maintenance trouble arising at such points. If after two or three years it is found that the original distribution of the circuits requires modification, it is a comparatively simple matter to open the stub cable and re-arrange the circuits for a further period. This method avoids repeated interference with the cable wires at junction points and other places along the line of cable; a practice which is always subject to abuse. 


\section{(5) House Cabling.}

In large hotels and office buildings where the demand for telephone service is on an extensive scale, arrangements are made for the initial installation of a complete cabling system carefully designed to meet the ultimate requirements of the building. The class of service required for hotels is somewhat different from that demanded by large office buildings, and the difference markedly affects the design of the cabling scheme.

(a) Hotels.-The number of telephones for hotels can be determined with fair accuracy, as practically every room (in some cases as many as 2500 ) is fitted with a telephone. Consequently the cable system can be laid out in advance on a permanent basis. Hotel telephone service is handled by means of a private branch exchange switchboard, located at some convenient point. All circuits, with the exception of junction lines, radiate from the exchange to distribution centres situated on the various floors. There are two general types of distribution in vogue, one in which the main cables (known as "riser" cables) are installed in a shaft with branch cables on each respective floor, and the other in which the cables are installed in conduits, small boxes being provided to accommodate the joints. The riser cables are attached to suspension strand wire, as in the case of exchange cables. It is not considered economical to open the riser cable at each floor, and therefore the cables are diminished at every third and fourth floor. From the diminishing points branch cables are taken to the floors above and below, and thence to distribution centres, where they are ended in terminal boxes suitably situated for the connection of the individual telephone wires.

The terminal box for internal distribution normally consists of a block of insulating material carrying a number of binding posts and a fanning strip which serves as a guide to preserve the arrangements of the individual twisted pairs. The posts and strips are mounted in a wooden box which can be fixed to the surface of the wall, or recessed into the wall if the installation work can be carried out before the building operations have been completed. Accommodation for wires from terminal boxes to the telephone instruments is afforded either by small conduits or by suitable mouldings along the walls of corridors and rooms.

Frequently the required lengths of cable are cut and the necessary jointing to branch cables or stubs carried out in a central workshop, instead of on site. There is much to commend this method, as the work is done in a better manner under workshop conditions, particularly when the cable has to be installed in a vertical shaft. The arrangement also provides work for elderly or partially-disabled jointers, whose services could not otherwise be retained. If the cable cannot be formed into a small coil suitable for transport to the site it is placed on a drum with the joints securely tied to prevent fracture due to bending close to the joints. The equipment of terminal boxes is also frequently completed in the workshop, in which case the only work remaining to be done on the site is a straight joint between the two cables provided. In damp situations silk and cotton-covered wire forms, boiled out in pot-head compound and painted with moisture-proof paint, are used, and the terminals are of metal instead of wood, unless local circumstances permit the use of the No. 14 external type of terminal.

(b) Office buildings.-In large office buildings arrangements vary considerably, according to the requirements of individual tenants. Some require a large number of out-going lines, with little or no internal service, while others desire branch exchanges with a large number of internal extension lines. A system of cabling sufficiently flexible to meet these conditions is arranged for by providing a distribution case or cross-connecting frame at some convenient point, usually in the basement. A certain number of the circuits in the main cables from the exchange, known as "feeder cable pairs." are jointed to the pairs in the riser cables ; they therefore terminate direct on the terminal boxes, whilst

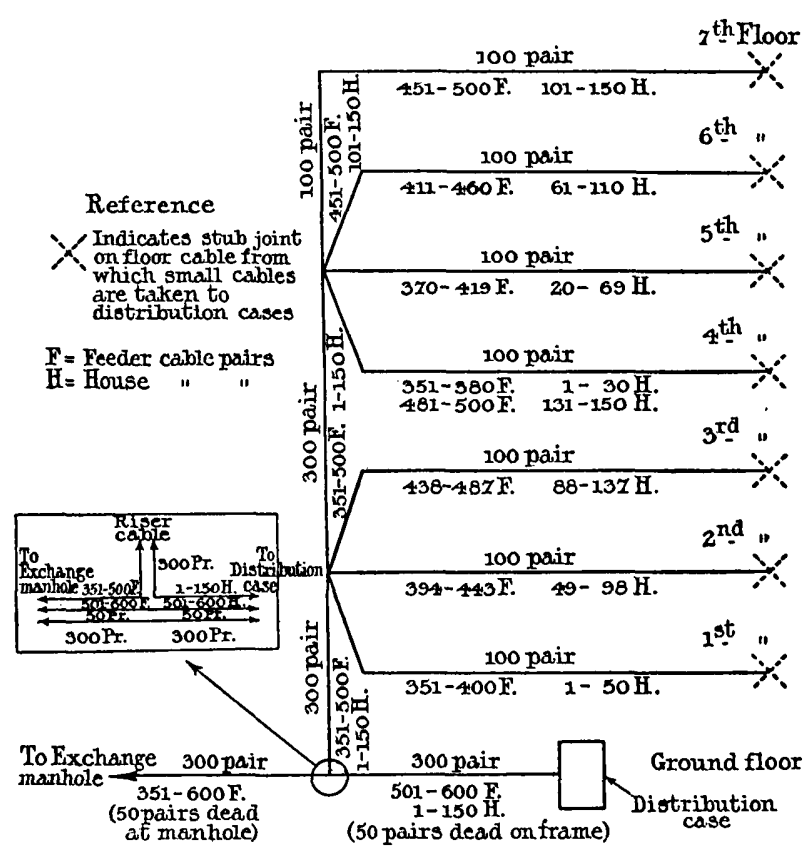

FIG. 28.-House cabling diagram.

the remainder of the wires in the main cable are taken to the frame. The remainder of the circuits in the riser cables, known as "house cable pairs," are brought to the connecting frame. Fig. 28 shows a small wiring diagram which illustrates the system.

From a maintenance point of view this arrangement is decidedly advantageous; it also avoids crowding the connecting frame with unnecessary circuits. By carefully arranging the number of pairs in the relative groups, a very flexible system of distribution, which enables additional exchange facilities and internal extensions to be afforded without delay, is obtained. In one large office building in New York, containing about one million square feet of renting area, four main cables, each of 900 pairs, are brought in from the neighbouring exchange; approximately 600 pairs in each cable are taken direct to the riser cables; and the remaining 300 pairs are taken to the connecting frame, which is similar to the intermediate distribution frame 
of a large telephone exchange. There are several 600 -pair riser cables serving the 22 floors of the building. This gives an idea of the magnitude of some house cabling lay-outs, the working plans for which are exceedingly complicated.

The distribution of the wires to terminals is arranged on the bridging or multipling system, i.e. one pair of wires is available for use on more than one floor. This increases the flexibility of the system, and fewer spares are required than if there were no multipling. The method of distribution from the wiring centres is practically the same as in hotels, unless there are private branch exchanges, in which case a lead-covered cable of suitable size is taken from the feeder cable direct to the switchboard concerned.

\section{(6) Block Cabling and Wiring.}

The advantages of the American "block" system, from a distribution point of view, were briefly mentioned under

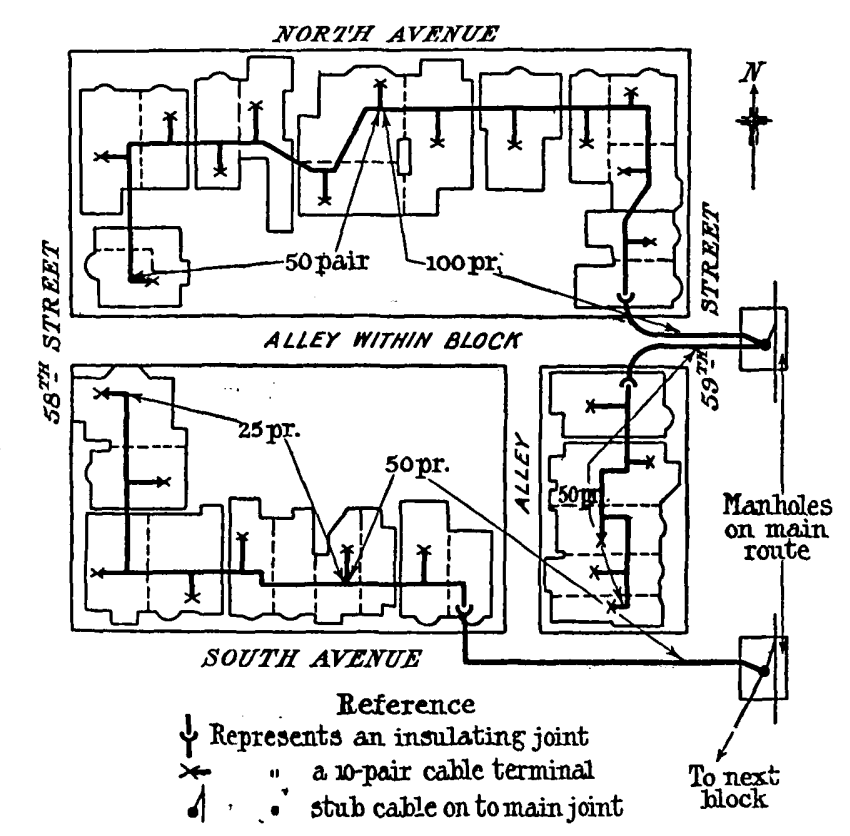

Section IV (Design and Lay-out). Where the telephone density is not sufficient to justify internal house cabling schemes, and is greater than could be served economically by a pole route, a system of block cabling is adopted. A branch cable from either an aerial or underground exchange cable is taken to some suitable point in the block, from which distribution can be made. If the buildings are continuous, cables are usually taken along the walls externally, with cable terminals fitted at intervals convenient for distribution. Cable clamps secured by means of wood screws are used for attaching cables to the walls of buildings. Holes are drilled in the centre of the bricks, and expansion shields are fitted to take the screws. All clamps are tapped to receive a bridle ring in case the latter is required for bridle-wire distribution. Where buildings are not continuous an aerial span must be introduced, suspen- sion strand and cable rings being utilized, as described in Section V (2). If, however, the distance does not exceed $15 \mathrm{ft}$., a short piece of iron pipe is let into the brickwork on either side. The cable is secured to this pipe by wrappings of soft galvanized iron wire. Where outlying buildings or other obstructions prevent a clear run on the face of the building, cables are frequently conveyed through the basements.

Fig. 29 shows a typical block consisting mainly of large apartment houses. Owing to the irregularity of the buildings, block cables are run internally through the basements. This type of house has usually a very good basement, on account of the furnaces required for the central-heating system. If there is a break in the continuity of the buildings the gap is bridged by means of a piece of iron pipe laid in the ground, through which the cable is drawn.

From a maintenance point of view the use of wood or iron fences for block cabling is discouraged.

For distributing purposes the No. 14 type of cable terminal is almost invariably used. Cable terminals can be obtained with tail pieces entering the terminal from the top or bottom, according to the position in which they are to be fixed, but, wherever possible, terminals are so placed that they are accessible to workmen without the aid of ladders. In that case the cable usually enters the terminal from above. Cable terminals are provided at frequent intervals, and circuits are multipled to two or more terminals in order to provide flexibility. Bridle wire led through bridle rings is utilized for connection to subscribers' telephones. Bridle wire consists of two No. 18 B. \& S. gauge tinned copper wires, insulated with rubber compound, covered with black weatherproof braid and twisted into a pair. To avoid confusion it should be mentioned that the terms "bridle wire" and "drop wire" are not synonymous. Bridle wire is not self-supporting and is intended only for use in bridle rings for block wiring and on poles for cross-connections. When more than six bridle wires are likely to be required on any run, the advisability of installing a cable is considered.

In the case of apartments or flats, generally four or five stories in height, bridle wires are frequently taken up dumb-waiter shafts to the floor required, thus avoiding ladder work.

One advantage which the telephone companies have from a plant-record point of view is that the fire insurance companies issue a large scaled set of plans for each town, showing each block in detail. To some extent a similar type of plan is available in this and other countries. The type and class of each building (e.g. brick, wood, number of floors, etc.) are clearly indicated. In return for a small annual subscription the insurance companies are willing to keep these maps up to date. Plant details can be recorded on these maps, so that any new order received for telephone connection can be at once localized and definite instructions given to the installation men without an actual survey being made.

Block cabling represents an exceedingly flexible system, and, after completion of the main scheme, telephone service can be readily supplied to any house in the block at small cost. 


\section{(7) Drop Wiring.}

Reference was made under Section V (1) to the use of covered wirc, known as "drop wiring," for distribution from polc routes to subscribers' premises. It plays such an important part in distribution that further mention of the system is desirable. Several stages in the development of distribution methods have been traversed since the days when distribution was effected by means of large numbers of open wires supported upon high poles. Now the standard method is to erect short poles ( 20 to $24 \mathrm{ft}$.) in the alleys within blocks or in the roadways; from these poles covered dropwires are run direct to the subscribers' premises.

In "thin" areas, where the telephone density does not justify external or internal block cabling and wiring, a carefully-designed acrial cable system, liberally provided with cable terminals, forms an economical system of distribution. It is far more effective than the provision of a few distribution poles connected direct to underground cables. Plant of this type is neat and inconspicuous, and does not raise any objections on resthetic grounds, with the result that the necessity for underground work may remain dormant for many years. At one time the underlying principle was that cables should be tapped as little as possible, but to-day there is nothing to be feared from a multiplicity of cable terminals which makes possible a system of covered drop-wire distribution.

The terminal is a vital part of the distribution system; therefore it has been carefully and substantially designed. Types Nos. 8 and 14 are now used exclusively. As their cost is only a small part of the total expense, there has been no temptation to sacrifice efficiency for cheapness.

The number of opening-out points depends upon the density of the subscribers' lines, but a liberal use of terminals is favoured in order to avoid running covered wires parallel with the main cable. Speaking generally, a terminal is used if $300 \mathrm{ft}$. of drop-wire will thereby be saved. Hence if it is expected that three subscribers' lines will radiate from each pole, a terminal is fitted initially on each pole, or at least on each alternate pole.

In addition to the factor of annual cost, another important element enters into the question of terminal versus drop-wire, viz. the number of men engaged and the time spent on installing the subscribers' lines. By the generous provision of terminals the size of the gang is reduced to a minimum. One man, with an assistant, can complete a drop-wire installation in a surprisingly short time, as all that is required is to tap a cable terminal at the front or back of the subscribers' premises and connect the lead thereto. Each drop-wire gang is usually supplied with a small motor van which carries all the materials and tools likely to be required. Such a gang can install, on the average, 8 to 10 lines in an 8-hour day.

No attempt is made to taper short lengths of distribution cable. It is claimed that such cable-usually 50-pair-must be regarded as similar to a gas or water main; something to be tapped for a subscriber's circuit at any point along its length. An 11- or 16-pair cable terminal is the usual size fitted, and some of the circuits are made available at two or more terminals in order to increase flexibility and avoid subsequent changes in arrangement of circuits.

The use of a large number of small cable terminals reduces the length of the subscribers' loop to a minimum. The policy of employing drop-wire of high-grade material has been adopted. The type now employed has a normal life of at least 10 years, and is used over and over again. When recovered, drop-wire is sent to the stores and is examined, the bad pieces are cut out, and the remainder is re-jointed ready for re-issue.

Drop-wires are terminated on small porcelain " knobs" which are carried by small rectangular galvanized brackets. The latter are attached either directly to the pole or to the guard-arm fitted on a joint-use pole. They carry one or two knobs and drop-wircs

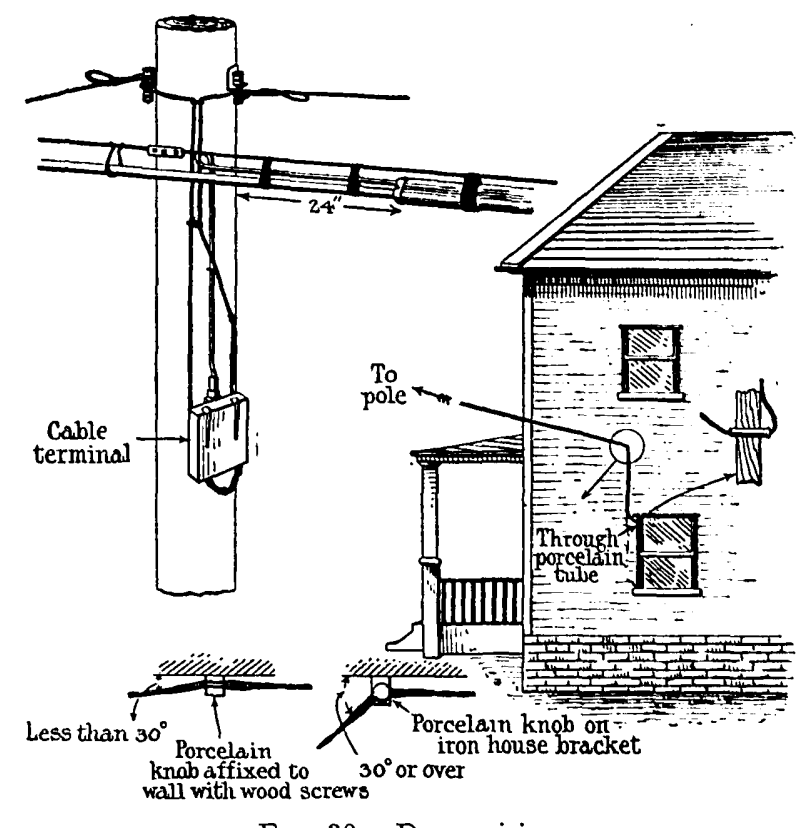

FIG. 30.-Drop wiring.

as required. A similar galvanized bracket is fixed on the subscriber's premises, and a direct lead into the building is then generally obtained, as shown in Fig. 30. If this arrangement is inconvenient, an additional bracket is fitted, or the drop-wire is taken along the face of the building in small bridle rings. A porcelain tube is inserted at the point of entrance to the building. A termination of this description is jointless, as it is taken direct from the cable terminal by way of the pole bracket and the house bracket to the window block fitted inside the subscriber's premises. It has a great advantage over open-wire distribution, where at least two changes are made-from cable to open wire, and from open wire to leading-in cableand where cross-connecting may be necessary if the wires are brought from the end of the arm.

The advantages claimed for this drop-wiring method of distribution may be briefly summarized :--

(1) Short poles may be used, as foliage and other 
obstructions do not affect covered drop-wires in the same way as they would open wires.

(2) Pole arms are not required, and the system of brackets and insulators involves the minimum of material.

(3) There is less danger of contact with high-tension wires.

(4) Short-circuits and contacts are avoided, and therefore maintenance costs and interruptions to service are reduced.

(5) The subscriber's loop between the terminal and the subscriber's premises is free from joints.

(6) The possibility of "humming" is lessened.

(7) Induction effects are reduced, as the wires are perfectly transposed.

(8) Telephone service can be supplied at short notice.

(9) The cost of running individual circuits after the main scheme has been completed is small.

In regard to (4) it might be mentioned that the last span of open wire is always a source of many faults ; in fact, it has invariably more than a proportionate number of faults.

\section{SECTION VI.}

\section{TRANSPORT.}

Motor transport is much more largely used on telephone work in America than in England for the following reasons :-

(a) The initial cost of trucks and cars is less.

(b) Petrol is retailed at about one-third the British price.

(c) Greater distances have to be covered.

(d) Construction and maintenance hands are paid at very high rates.

(e) It is difficult to obtain convenient accommodation in country districts.

Under the conditions existing in America, in fact, it is a comparatively simple matter to prove economy by the use of motor transport. In country work, instead of construction hands camping out, arrangements are frequently made to board them at the nearest village, from which they are conveyed to the site of work each day. Three-ton trucks are used for this purpose and also for the transport of small bodies of workmen, tools, and materials from one point to another during the course of the day.

Each gang forcman, who may control from 10 to 20 men, is usually supplied with a two-seater car, fitted with a box body. This enables him to supervise the work closely, and also to convey the small stores which may be required. Motor cycles are used to a limited extent for maintenance purposes, but not on construction work, for which they are not considered reliable or adaptable.

As will be seen from the lantern slides, the truck used by an overhead construction gang is fitted up as a travelling store-room. Along the two sides of the truck small partitions are provided for carrying the stocks of bolts, insulators, screws, etc., which are required for a large job. The necessity for issuing small quanti- ties from the main stores during the progress of the work is thus avoided. The truck is also designed to carry ladders, ropes, tree-cutters and other gear. A first-aid box is carried on every gang truck.

The amount of "dead time" on construction work has been greatly reduced through the use of these trucks. Even in town work they are most useful, as they convey men and stores direct to the site of operations in the shortest space of time.

The great use made of transport by the telephone companies has necessitated the building of large garages and the employment of a special staff of men for dealing with repairs. The New York Telephone Company, for instance, has a fleet of over 1000 vehicles of various descriptions, and a staff of 250 engaged on maintenance and repairs. Nevertheless, the companies are satisfied that such expense is fully justified by the resulting improvement in efficiency.

\section{SECTION VII.}

\section{Mechanical and Labour-saving Devices.}

The high rates of pay in America have necessitated the use of many labour-saving appliances. Owing to the large increase in wages in this country during the past five or six years, the following particulars of some of the machines used may be of interest:-

(a) Excavating machines for trench work.-A small machine, known as a "ditching machine," particularly useful in excavating the shallow trench required for telephone conduits, has been developed. At the rear of a small traction engine is fitted a wheel about $6 \mathrm{ft}$. in diameter, which can be lowered at will. The periphery carries several bucket-shaped prongs which penetrate the ground and throw the excavated soil to one side. $A$ trench 19 to 24 inches wide up to a depth of $5 \frac{1}{2} \mathrm{ft}$. can be formed by this machine. It is suitable for footway and roadway work where there are not many obstructions. Details of the obstructions are usually ascertained in advance, and the machine can be so controlled that it is stopped within a few inches of any obstacle. The prongs will cut through an ordinary macadam roadway without difficulty, and on country roads a speed of $7 \mathrm{ft}$. per minute can be attained.

(b) Back fillers.-A modified form of a farmer's plough is used for pushing the ground back into the trench ready for ramming. Two men are required to guide the plough, which is drawn by the steel wire rope on the winch of a motor truck.

(c) Tamping machines.-The difficulties of handramming have been overcome by the use of a mechanical tamper. A 12-in. square block weighing $150 \mathrm{lb}$. is elevated $4 \mathrm{ft}$. by gearing driven by a small petrol engine, and then released. Thirty blows a minute can be delivered whilst the machine is travelling horizontally at $3 \mathrm{ft}$. per minute. This machine can do as much work as 10 men, each armed with 10-1b. rammers (or punners). To fill in a trench $2 \mathrm{ft}$. deep the back filler and tamping machine traverse the course twice.

(d) Concrete mixers.-For laying a concrete foundation, forming the sides or top protection of a conduit route, 
or supplying the concrete for manholes, a concrete mixer fitted on a motor truck has been evolved. The gravel and sand are mixed at a yard and raised into hoppers on the truck by means of a small motor-driven conveyer. A tank on the truck is filled with water. When on the job a quantity of the gravel and sand is released from the hoppers and fed into the mixer; cement and water are added and the mixer is rotated by gearing connected with the mixer engine. A movable trough is used to convey the concrete to the trenches or manhole, where it is levelled by hand.

(e) Pole-hole excavators.-A 3-ton truck is used to carry a large auger capable of making a hole from 18 to 24 inches in diameter up to $6 \mathrm{ft}$. deep. Power is supplied from the truck motor to various trains of gearing which in turn rotate the auger at the rate of 60 r.p.m. A revolving turntable on the truck permits the hole to be excavated from either side or from the rear of the truck. A pole-hole $6 \mathrm{ft}$. in depth can be excavated in from 3 to 5 minutes in various types of sub-soil. Clay and even hardpan offer little resistance to the auger-the only serious obstacle being actual rock. The operation of the machine is controlled by two men, one acting as driver, and the other as augeroperator. Manipulation is effected by means of two levers, one for engaging the up-and-down feed, and the other for engaging and disengaging the auger driving clutch. After boring has been continued for some time the auger is raised, bringing with it all the earth excavated. The earth is then quickly dispersed by the rotation of the auger. The latter can be tilted for boring at an angle, as for example, in excavating a stay-hole.

In a more recent type the truck is fitted with a derrick, which is capable of erecting the pole upon completion of the excavation. The author witnessed the erection of $45-\mathrm{ft}$. poles in a back-alley in Detroit by means of this equipment. In each case the sub-soil was a hard clay, and it took the machine $4 \frac{1}{2}$ minutes to bore a 6 - $\mathrm{ft}$. hole, and a total of $6 \frac{1}{2}$ minutes to place the pole in position ready for tamping. One foreman and two skilled men represented the total gang.

(f) Pole erectors.-All telephone companies have a certain number of 3-ton trucks fitted with derricks for pole erection. The derrick is normally carried on the side of the truck, but can be placed in position for pole erection in a few minutes. On country roads where the poles are laid out along the road in advance and where the holes have been excavated it is possible to erect 25 - $\mathrm{ft}$. poles at the rate of about 40 per hour under favourable conditions. The maximum number erected on an 8-hour day by one foreman and eight men using one 3-ton truck is 300 . The same derrick can also be usefully employed for withdrawing the old stump of a pole when replacement is necessary.

(g) Installation of loading coils.-The 3-ton trucks are fitted with a small type of derrick or shear-legs designed for lowering loading-coil pots into manholes. An alternative method adopted by some of the telephone companies is to fit the truck with an overhead runway, consisting of an $H$ girder which overhangs the rear of the truck. By means of block and tackle the loadingcoil pots are lifted off the floor of the truck, run along to the end of the girder, and lowered into the manhole.

(h) Pumps.-A centrifugal pump, capable of emptying manholes at the rate of $\mathbf{3 0 0}$ gallons per minute, is fitted to trucks used on underground construction or maintenance work. The pump is driven from the engine of the truck.

(i) Motor winch for cable installation.-The majority of the Bell telephone companies use a power-driven winch fitted on a 3-ton motor truck for the installation of cable. The winch is usually 24 inches between flanges, with a 10-inch barrel, and is fitted immediately behind the driver's cab. It carries about $1000 \mathrm{ft}$. of $\frac{5}{8}$-inch steel wire rope for hauling the cable. The winding gear is fitted with an auxiliary clutch box (driven from the truck's transmission gear) and a suitable reduction gear. This truck can also be used for carrying two drums of cable, and the winch is then useful for raising and lowering the cable on the loading ramps. By a simple movement of a single lever the load can be lifted, held, or lowered. The rate for drawing-in cable under normal conditions is about $50 \mathrm{ft}$. per minute.

(j) Air-driven drilling machines.-Where rock is encountered during the excavation of trenches for duct work or for pole erection, portable pneumatic drilling machines are frequently used. A $1 \frac{1}{2}$-inch hole can be drilled $3 \mathrm{ft}$. deep in solid rock in from 7 to 8 minutes, after which a charge of dynamite is inserted. The surrounding rock, being thus shattered, can be cleared out by ordinary means.

\section{SECTION VIII}

\section{Maintenance.}

Throughout the associated companies in America there appears to be a keen spirit of "Service First," so that the public shall have no legitimate ground for complaint. Under pre-war conditions the time taken for clearing faults in large cities was reduced to an average of about two hours per fault. This was made possible by the concentration of all testing and localizing apparatus in one central office. In New York, for example, there is a central test-office in the southern portion of Manhattan which does all the testing for 20 exchanges, embracing about 260000 stations, just as if the testing apparatus were located in the apparatus room of each. When a fault is reported the test clerk stationed at the exchange concerned telephones the details to the central test-office and connects the faulty line to a junction between the two offices. Necessary instructions are conveyed by means of loud-speaking telephones fitted at several parts of the apparatus floor of the exchange concerned. If a fault is proved to be outside the exchange, details are passed on to the fault-distribution officer, who is in telephonic communication with all the linesmen. Each large building, block, or group of blocks, is considered for maintenance purposes as a unit under the control of one man. The distribution officer has a large-scale map of the territory on the wall, with a small hook placed in the centre of each maintenance section. A 
ticket showing details of each current fault in this section is placed on the hook so that the necessary instructions can be given to the responsible linesman. Instrument faults which cannot be quickly remedied on site are dealt with by changing the instrument, the defective one being handed over to mechanics for repair.

Linesmen are provided with motor cycles or even small cars, when their use can be justified, to enable them to deal with long-distance subscribers' line faults. Toll line routes are divided into sections, and each section linesman has a two-seater Ford car fitted with a small box body, in which can be carried small quantities of any type of line material likely to be required. These section linesmen are also furnished with an exchange telephone at their private residences, so that they may be called out at any time in case of emergency.

Breakdowns of telephone line plant due to heavy sleet storms are now being considerably reduced by the more extended use of cable instead of open wire. As mentioned earlier in the paper, there is little danger of an overhead route being brought down when carrying cable only.

As it is not customary to impose pressure-tests upon completed cable works, or to use desiccators for raising low cable insulation, it might be expected that the maintenance of underground cables suffers in consequence. In practice this is not the case. In the central testing-offices careful records of all faults in underground cables are kept, and, if more than two or three pairs have to be changed over in the same cable for the purpose of clearing faults, suspicion is aroused and the necessary localization tests are at once made with a view to determining the cause of the trouble. In this way incipient faults are generally detected and remedied. The universal practice of boiling-out all cable joints tends to delay a complete cable breakdown from any cause other than mechanical injury.

$A s$ a rule the provision of spare conduits is on a liberal scale, and a small stock of each size of cable is usually available in the vicinity of the main routes. The construction gangs are thus able to introduce a new length of cable into a duct adjacent to the one containing the faulty cable and change over the circuits within a few hours of a warning being given.

\section{SECTION IX.}

\section{CONCLUSION.}

There is one feature which might be emphasized in connection with telephone construction work in the States. When the speed at which the work is carried out was first realized, it was imagined that the quality of the work would necessarily suffer. Investigation showed, however, that this was not the case. Therc are several reasons for this unexpected combination of high quality and rapid output. The ready acceptance of machinery and labour-saving devices by the working man, and the fact that they have been used to their full capacity, have been conducive to high efficiency. Trade unionism exists to some extent, but there is no desire to hamper output. The men readily accept any suggestion for speeding up the work, as they believe it will be to their advantage to reduce costs ; in consequence it has been possible to place the majority of telephone workmen on the staff of the various companies rather than on an hourly basis. They receive a good weekly wage and enjoy privileges in regard to holidays, sickness, pensions, etc., which attract a good class of man. Another important point is the prospect of promotion to the higher grades for all ranks. It is a fact that any position in the Bell System is open to anyone who becomes qualified for it. Amongst the jointers are men who have graduated in a university; they have started at the bottom but are not content to remain there. The actual hours worked are not long, but while the men are on duty they work hard and well.

The author desires to express his thanks to the engineers and superintendents of the American Telephone and Telegraph Company and the New York Telephone Company for supplying information and illustrations and for their permission, subsequently obtained through the Western Electric Company, to make use of such data in this paper. The photographs of various sections of plant work which have been shown upon the screen were presented by the Plant Department of the New York Telephone Company. Reference must also be made to the valuable assistance given by the staff of the Illinois Bell Telephone Company, the Michigan State Telephone Company, and many others.

\section{Discussion at The Institution, 17th November, 1921.}

Sir Andrew Ogilvie: The great importance of the author's careful study of American practice in a very important branch of telephone work will be readily agreed. I shall however, confine my remarks to a few points which relate to general administration. The paper states that the A.T. \& T. Co. controls 12 million telephone stations. That is the total number of stations which can be reached through the Bell system, but it includes, besides the 8 million stations of the federated Bell companies, about 4 million stations belonging to independent companies which cannot strictly be said to be under the control of the A.T. \& T. Co. I do not say this with any desire to disparage the work of that company, because it is an institution for which $I$ have the profoundest admiration. The paper gives a very interesting account of the functional and territorial organization of the Bell companies. It refers also. but not so fully, to the splendid standardizing and research organization which the company maintains at its headquarters. That organization includes some 1200 real experts in every branch of telephone work, and also, more recently, in telegraph and wireless work, and it is without parallel in the world. These experts are not executive officers ; they are purely scientific people who are studying the problems of telephone work arising in the magnificent field of experience in the vast systems of the Bell companies. The paper also calls 